\title{
Role of Oceanic and Land Moisture Sources and Transport in the Seasonal and Interannual Variability of Summer Monsoon in India ${ }^{\mathscr{O}}$
}

\author{
AMEY PATHAK \\ Department of Civil Engineering, Indian Institute of Technology Bombay, Mumbai, India \\ SubIMAL GHOSH \\ Department of Civil Engineering, and Interdisciplinary Program in Climate Studies, Indian Institute of Technology \\ Bombay, Mumbai, India \\ J. Alejandro Martinez \\ Institute of Physics, University of Antioquia, Medellin, Colombia \\ FRANCINA DOMINGUEZ \\ Department of Atmospheric Sciences, University of Illinois at Urbana-Champaign, Urbana, Illinois \\ PRAVEEN KUMAR \\ Civil and Environmental Engineering, University of Illinois at Urbana-Champaign, Urbana, Illinois
}

(Manuscript received 24 February 2016, in final form 9 September 2016)

\begin{abstract}
Three key issues of moisture supply and Indian summer monsoon rainfall (ISMR) variability are discussed in the present work: identification of the oceanic and terrestrial sources of moisture; the extent to which each source affects the ISMR; and their individual contributions to the interannual variability of ISMR. The modified Dynamic Recycling Model, based on a Lagrangian trajectory approach, is used to estimate the relative contributions from 27 terrestrial and oceanic moisture source regions to the monsoon during 19792013. ERA-Interim data are used for the study. The results show that the ISMR is strongly influenced by the land-ocean-atmosphere interactions, and a significant fraction of atmospheric moisture to the ISMR comes from five main moisture sources: the western Indian Ocean (WIO), central Indian Ocean (CIO), upper Indian Ocean (UIO), Ganges basin (GB), and Red Sea and the neighboring gulf (RDG). The moisture flux from WIO is very high during the initial period of monsoon seasons. From the mid-monsoon season, the contribution from this moisture source decays and land sources through evapotranspiration (ET) become more active. Early decay of moisture contributions from the WIO and the GB is observed during weak monsoon years. El Niño years are associated with low contributions of moisture from all sources, whereas warm Indian Ocean years are associated with low moisture flux from the major sources except WIO. ISMR is characterized by the prolonged and increasing moisture supply from WIO during the first half of the monsoon along with contributions from GB during the end of season. The results are consistent across several reanalyses (CFSR, ERA-Interim, and MERRA).
\end{abstract}

Supplemental information related to this paper is available at the Journals Online website: http://dx.doi.org/10.1175/ JCLI-D-16-0156.s1.

Corresponding author e-mail: Subimal Ghosh, subimal@civil. iitb.ac.in

\section{Introduction}

The Indian summer monsoon rainfall (ISMR), which meets a major proportion of annual water demand over the Indian region (Yasunari 1991; Dirmeyer 1998; Gadgil 2003), has wide ranges of temporal variability: namely, intraseasonal to interannual and multidecadal. 
Among all these scales of temporal variations, the interannual variation of ISMR has significant impact on seasonal water availability and, therefore, severely affects the gross domestic product (GDP) of India (Gadgil 2003). Although the interannual variability of the Indian summer monsoon has been extensively studied, its causes are yet to be fully understood. Hence, understanding the different physical processes responsible for strong and weak seasonal rainfall is of the utmost importance in order to accurately model and predict the interannual variations in monsoon precipitation.

The Indian summer monsoon is generally identified as a manifestation of seasonal migration of the intertropical convergence zone (ITCZ) to the northern latitudes, resulting in a seasonal reversal of wind circulations and the amount of precipitation over the subcontinent. The ISMR is observed to be associated with large-scale climate processes, such as cyclonic vorticity at $850 \mathrm{hPa}$, seasonal low-level westerly jet over the western Indian Ocean, reversed vorticity at upper-atmospheric levels (200 hPa) (Lim et al. 2002; Goswami 2005), the anticyclone over the western Pacific, and high moisture convergence over the monsoon trough. In addition, the monsoon rainfall over India also has a strong link with the sea surface temperature (SST) variability over the Pacific and Indian Oceans (Trenberth et al. 2006; Mishra et al. 2012; Levine and Turner 2012; Sabin et al. 2013; Roxy 2013; Sandeep and Ajayamohan 2014) and Eurasian snow cover (Yasunari 1991; Douville and Royer 1996; Robock et al. 2003; Yang et al. 2004). Large-scale phenomena due to the variations in SST, such as the El Niño-Southern Oscillation (ENSO), Indian Ocean dipole (IOD), and tropical biennial oscillation (TBO), are also strongly coupled with the seasonal rainfall during ISMR. The influences of different physical processes make ISMR a complex geophysical phenomenon. Hence, modeling the interannual variability of ISMR has remained an elusive task thus far.

Although monsoon rainfall results directly from the transport of atmospheric moisture, relatively less importance is given to this transport phenomenon in earlier studies. The seasonal reversal of wind during the summer monsoon results in the advection of oceanic moisture from the Indian Ocean toward the Indian subcontinent. Rainfall during the summer monsoon is regulated by the strength of atmospheric transport of oceanic water vapor; but the subcontinental land also contributes significantly to the total amount of rainfall (Pathak et al. 2014). The relative contribution from different sources varies across space and time, during strong and weak summer monsoon years. Therefore, the atmospheric moisture transport from different evaporative sources to the sink over India should be studied to understand the reason behind the interannual variability of ISMR, especially its origin, evolution, retreat, and variability over the Indian subcontinent.
To quantify the contribution of atmospheric moisture from a source to a sink region, different methods have been developed over the years that can be broadly classified into analytical models (Budyko 1974; Dominguez et al. 2006; Burde 2006; Van der Ent et al. 2010; Keys et al. 2012; Ordóñez et al. 2012; Martinez and Dominguez 2014), numerical water vapor tracers (Joussaume et al. 1984; Koster et al. 1986; Bosilovich and Schubert 2002; Stohl and James 2005), and physical water vapor tracers using isotopes (Salati et al. 1979; Friedman et al. 1992; Henderson-Sellers et al. 2002). The numerical methods can be classified into (i) Eulerian methods and (ii) Lagrangian methods. Eulerian methods deal with the water balance at fixed locations as time varies. This is normally achieved by introducing water vapor tracers into the numerical model (Joussaume et al. 1984; Koster et al. 1986; Bosilovich and Schubert 2002). The water vapor tracers are initialized with moisture source label/tag and then undergo different physical processes in the model, such as evaporation, condensation, precipitation, convection, advection, etc. The advantage of the Eulerian approach is that it can give detailed insights of the atmospheric water cycle; however, the complexity of the physical model and the high computational cost are the limitations of this approach (Winschall et al. 2014). Lagrangian models, on the other hand, are based on studying the water vapor budget of air parcels as they travel either forward or backward in time and space (Lim et al. 2002; Bosilovich and Schubert 2002; Stohl and James 2005; Dirmeyer and Brubaker 2007; Gimeno et al. 2010; Van der Ent et al. 2010; Tuinenburg et al. 2012; Dominguez et al. 2006; Martinez and Dominguez 2014).

Gimeno et al. (2010), using the 3D Lagrangian Flexible Particle Dispersion Model (FLEXPART) (Stohl and James 2004, 2005) at global scale, identified six different moisture source regions for the ISMR: namely, the Indian Ocean, the Arabian Sea, the Zanzibar Current, the Agulhas Current, western Africa, and the Red Sea. Van der Ent et al. (2010) used a water accounting model to demonstrate the importance of terrestrial moisture sources (i.e., continental evaporation) for precipitation at the global scale. The maximum amount of continental moisture recycling ratio over India $(\sim 20 \%-40 \%)$, is observed during July in their study. Ordóñez et al. (2012) identified four major source regions for monsoon rainfall over western and southern India: namely, the Arabian Sea and the Indian Ocean (through the Somali low-level jet), the northwestern part of the Indian subcontinent, western and southern India (through evapotranspiration), and the Bay of Bengal during the winter season. Similarly, using a Lagrangian approach, Mei et al. (2015) analyzed the moisture transport from four different moisture source regions: namely, the Arabian Sea (19.6\%), land regions 
TABLE 1. Mean of moisture fraction originating from different sources that contribute to ISMR.

\begin{tabular}{|c|c|c|}
\hline Region name (numbers) & Mean JJAS moisture fraction & Total contribution to core monsoon zone rainfall $(\mathrm{mm})$ \\
\hline Western Indian Ocean (25) & 0.261843 & 393.2713 \\
\hline Central Indian Ocean (20) & 0.098266 & 155.0084 \\
\hline Red Sea and neighboring gulf (19) & 0.08163 & 116.3652 \\
\hline Ganges basin (12) & 0.080604 & 147.7151 \\
\hline Central Asia (3) & 0.045917 & 62.64438 \\
\hline Upper Indian Ocean (26) & 0.044169 & 81.28565 \\
\hline South-central forest (14) & 0.042564 & 86.31156 \\
\hline Eastern Pakistan (11) & 0.034393 & 53.90474 \\
\hline East Africa (22) & 0.027766 & 43.74651 \\
\hline South-central forest (14) & 0.042564 & 47.17086 \\
\hline Greater Iran (10) & 0.025992 & 32.52175 \\
\hline Continental water bodies (5) & 0.017925 & 24.5906 \\
\hline Southwest Russia (1) & 0.017883 & 23.95509 \\
\hline Arabian Peninsula (21) & 0.017227 & 24.87174 \\
\hline Southern Indian Ocean (4) & 0.011933 & 18.81784 \\
\hline Northeast Indian subcontinent (16) & 0.006438 & 12.12841 \\
\hline Southeast Russia (2) & 0.003092 & 4.136759 \\
\hline Northern China (6) & 0.002952 & 3.949789 \\
\hline Southeast Asia (9) & 0.001809 & 3.442325 \\
\hline Western Pacific Ocean (8) & 0.001524 & 2.773398 \\
\hline Western Ghats forest (27) & 0.0013 & 2.169639 \\
\hline Tibetan Plateau (7) & 0.000638 & 1.152862 \\
\hline Southeastern China I (17) & 0.000576 & 1.095857 \\
\hline North Pacific Ocean (24) & 0.000381 & 0.695697 \\
\hline Himalayan forest (15) & 0.000267 & 0.48306 \\
\hline Southeastern China II (18) & 0.000222 & 0.425865 \\
\hline
\end{tabular}

$(30.4 \%)$, the Bay of Bengal (4\%), and remote sources $(46 \%)$ during the summer monsoon in South Asia.

Though some attempts have been made to study the moisture transport for ISMR, the variability associated with moisture transport and its influence on seasonal rainfall has not yet been explored. This leads to diverse opinions and gaps in quantification and modeling of interannual variability of ISMR. The present study aims to analyze the atmospheric moisture transport from oceanic and terrestrial sources to India and their influence on interannual variability of ISMR. We use the Lagrangian approach developed by Dominguez et al. (2006) and Martinez and Dominguez (2014). The analysis is performed at daily time scale for the months of June-September (JJAS) at a spatial resolution of $0.75^{\circ} \times 0.75^{\circ}$. The contributions from several moisture source regions to the rainfall over India and the associated variability are studied.

\section{Data and methodology}

\section{a. Study area}

We subdivided the identified monsoon domain $\left(30^{\circ}-\right.$ $135^{\circ} \mathrm{E}$ and $55.5^{\circ} \mathrm{N}-40.5^{\circ} \mathrm{S}$ ) into 20 terrestrial and 7 oceanic regions. Table 1 shows the list of different source regions selected in the present study. Figure 1 shows the geographic location and extent of the different source regions. The land-atmosphere interactions through different hydrological feedbacks can significantly alter the precipitation over the land region. Hence, the terrestrial region boundaries are approximately selected on the basis of uniform climate subtype (Köppen climate classification: Kottek et al. 2006) and percentage forest cover (Hansen et al. 2013a,b) in the year 2000 (Fig. 1c). Among the terrestrial sources, region 11 is an arid region, region 12 is the Ganges basin, region 13 is peninsular India, region 14 is the east coast forest region, and region 27 is the Western Ghats region. The feedback from these land regions to monsoon precipitation is quantified separately. The box (hatched region) shown in Fig. 1 presents the core monsoon region, as mentioned by Rajeevan et al. (2010).

Evaporation over the oceans is an important net source of atmospheric moisture (Gimeno et al. 2012), particularly those regions where the rate of evaporation generally exceeds the rate of precipitation. The amount of oceanic atmospheric moisture transport to India depends upon the rate of evaporation compared to the precipitation over different oceanic regions. The regions with a high vertically integrated moisture flux divergence are considered as the potential sources of atmospheric 

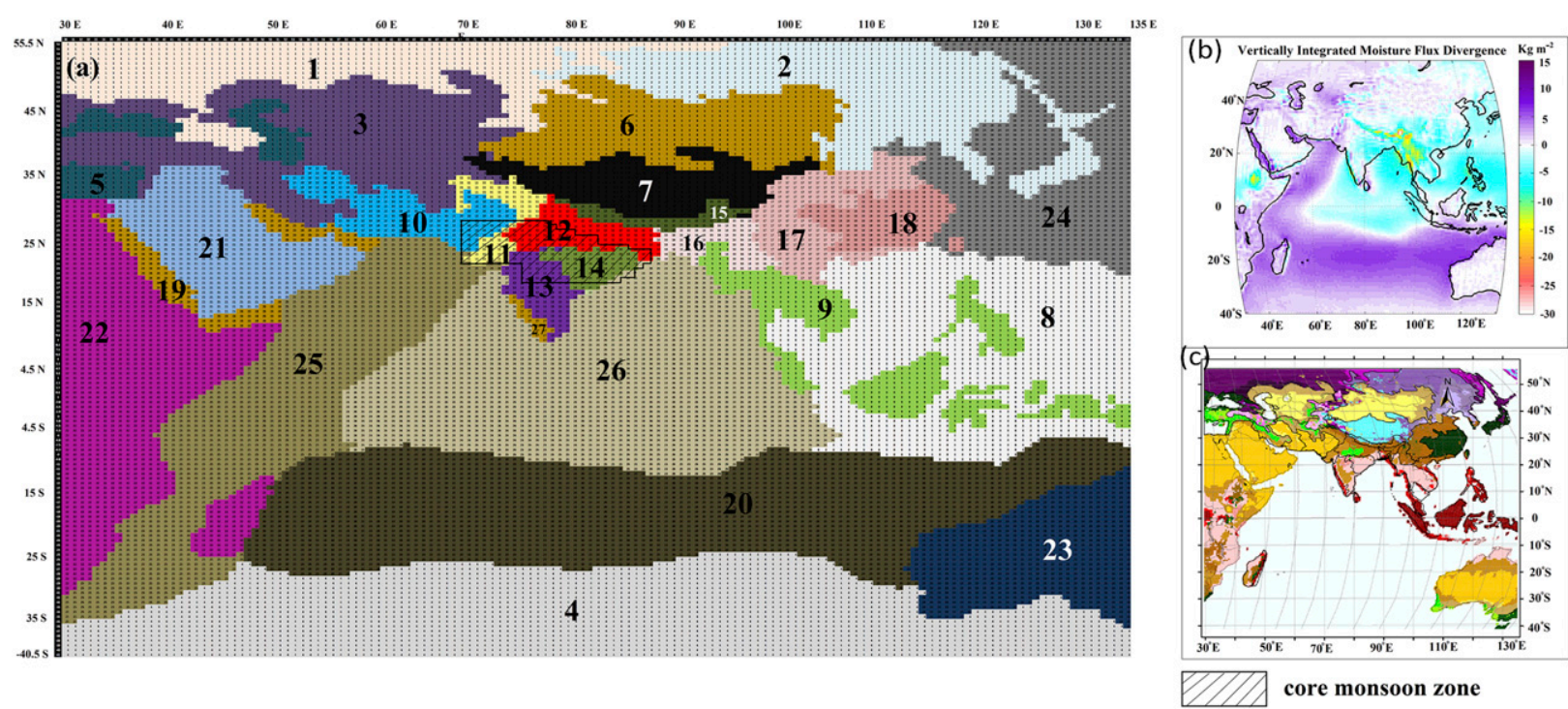

FIG. 1. (a) Regions considered as sources of moisture to ISMR. Regions over the ocean are based on (b) vertically integrated moisture flux divergence; and land regions are defined by (c) similar (approximately) climate subtype (Köppen climate classification: Kottek et al. 2006).

moisture, whereas regions with high convergence are considered as potential sink regions. Therefore, in the present study the oceanic sources are subdivided into seven different regions based on moisture flux convergence, using the divergence of the vertically integrated horizontal moisture flux (Fig. 1b) obtained from the European Centre for Medium-Range Weather Forecasts (ECMWF) interim reanalysis (ERA-Interim) archive.

\section{b. Data used}

In the present study, we use the ERA-Interim global dataset, available at $0.75^{\circ}$ spatial resolution, and at 37 atmospheric levels. In general, the hydrological cycle and atmospheric moisture transport are well represented in the ERA-Interim dataset (Dee et al. 2011). We use daily averages of evaporation $E$, total column water vapor $W$, and precipitation $P$ for 1979-2013. We also use the vertical integral of eastward and northward water vapor flux $\left(Q_{x}\right.$ and $Q_{y}$ ) to obtain the moisture-weighted wind component in two horizontal directions $\left(U=Q_{x} / W\right.$ and $\left.V=Q_{y} / W\right)$. The 6-hourly values of moisture-weighted eastward and northward winds are used in this analysis. The atmospheric pressure level data used for this study are from $1000-300 \mathrm{hPa}$.

\section{c. Methodology}

The Lagrangian approach of Martinez and Dominguez (2014) is an extension of the Dynamic Recycling Model (DRM) developed by Dominguez et al. (2006). In the original version of the DRM (Dominguez et al. 2006), the water vapor prior to precipitation over a region (sink) was traced backward in time, and the contribution from the same region was quantified. The recycling ratio (i.e., fraction of moisture originated from the same region) was mathematically derived as follows (Dominguez et al. 2006):

$$
R(\chi, \xi, t)=1-\exp \left[-\int_{0}^{\tau^{\prime}} \frac{\varepsilon\left(x, y, \tau^{\prime}\right)}{\omega\left(x, y, \tau^{\prime}\right)} \partial \tau^{\prime}\right] .
$$

Here, $R$ represents the fraction of moisture along the trajectory between time $\tau^{\prime}$ and $0, \varepsilon / \omega$ represents the ratio of evaporation to the precipitable water along the same trajectory. Martinez and Dominguez (2014) have modified this model to consider different source regions. The model



FIG. 2. Schematic representation of the moisture trajectory. The yellow circles are points where the trajectory crosses the boundary of the region. 
is illustrated in Fig. 2, which shows the schematic representation of the trajectory (starting at point $a$ and ending at point $h$ ) of an air column that acquires water vapor from six different regions (i.e., region 20, 26, 25, 13, 14, and 12, respectively), prior to precipitation over the sink location $[x(t), y(t)]$ in 12 .

The fraction of precipitation generated from two adjoining evaporative sources, for example regions 12 and 14 , can be obtained by calculating the $\varepsilon / \omega$ ratio along the path of the trajectory segment $f-h$. The fractions of atmospheric water present in the trajectory between the points $\left[x\left(t_{h}\right), y\left(t_{h}\right)\right]$ to the $\left[x\left(\tau_{f}\right), y\left(\tau_{f}\right)\right]$, resulting from evaporation in region 12 and region 14 are given by

$$
\begin{aligned}
R\left(\chi, \xi, t_{h}\right) & =1-\exp \left[-\int_{\tau_{f}}^{t_{h}} \frac{\varepsilon\left(x, y, \tau^{\prime}\right)}{\omega\left(x, y, \tau^{\prime}\right)} \partial \tau^{\prime}\right] \\
& =R_{12}\left(\chi, \xi, t_{h}\right)+\alpha_{12}\left(\chi, \xi, t_{h}\right) R_{14}\left(\chi, \xi, t_{h}\right), \\
\text { where } & R_{12}\left(\chi, \xi, t_{h}\right)=1-\exp \left[-\int_{\tau_{g}}^{\tau_{h}} \frac{\varepsilon\left(x, y, \tau^{\prime}\right)}{\omega\left(x, y, \tau^{\prime}\right)} \partial \tau^{\prime}\right]
\end{aligned}
$$

$$
R_{14}\left(\chi, \xi, t_{h}\right)=1-\exp \left[-\int_{\tau_{f}}^{\tau_{g}} \frac{\varepsilon\left(x, y, \tau^{\prime}\right)}{\omega\left(x, y, \tau^{\prime}\right)} \partial \tau^{\prime}\right], \quad \text { and }
$$

$\alpha_{12}\left(\chi, \xi, t_{h}\right)=1-R_{12}\left(\chi, \xi, t_{h}\right)$

Here, $R_{12}$ and $R_{14}$ represent the fractions of evaporated moisture collected from two regions (14 and 12) that are along the trajectory between the points $\left[x\left(t_{h}\right), y\left(t_{h}\right)\right]$ and $\left[x\left(\tau_{f}\right), y\left(\tau_{f}\right)\right] \alpha_{12}$ represents the fraction of evaporated moisture from region 14 along the trajectory, which is not lost (via precipitation) in the intermediate part of trajectory in region 12 . Similarly, the net moisture contributions from different sources along the trajectory can be quantified by calculating the moisture fraction corresponding to each of the source regions.

In Fig. 2, a trajectory $a-h$ consists of seven segments [viz., $S_{7}(a-b), S_{6}(b-c), S_{5}(c-d), S_{4}(d-e), S_{3}(e-f), S_{2}(f-g)$, and $S_{1}(g-h)$ ]. Additionally, the fractions of moisture collected from these seven different segments that fall under source regions $20,26,25,13,14$, and 12 , are represented by $R_{6}, R_{5}, R_{4}, R_{3}, R_{2}$, and $R_{1}$, respectively. Therefore, the total contribution at sink $\left(\chi, \xi, t_{h}\right)$ from all the segments within the source regions sr, and along the trajectory of the air column, are grouped as follows:

$a_{\mathrm{sr}}\left(\chi, \xi, t_{h}\right)=\sum_{S_{i} \in \mathrm{sr}}\left[\prod_{j=1}^{S_{i}-1} \alpha_{j}\left(\chi, \xi, t_{h}\right)\right] R_{S_{i}}\left(\chi, \xi, t_{h}\right)$.

Similarly, the total contribution from all the segments $\left(S_{i}: S_{i}=1,2, \ldots, 7\right)$ along the whole trajectory is calculated by adding the individual contributions. The fraction of moisture on a sink location $\left(\chi, \xi, t_{h}\right)$ that originated as evaporation within the entire domain is given by

$$
R(\chi, \xi, t)=\sum_{\text {sr } \in \text { Domain }} a_{\mathrm{sr}}\left(\chi, \xi, t_{h}\right) .
$$

The precipitation generated over a sink region $n$; that is, $\mathrm{SN}_{n}$ that results from evaporation over the source region $m$ (i.e., $\mathrm{SR}_{m}$ ), for any day $t_{h}$ is calculated as follows:

$P_{r}\left(\mathrm{SR}_{m}, \mathrm{SN}_{n}, t_{h}\right)=\frac{\sum_{(\chi, \xi) \in \mathrm{SN}_{n}} a_{\mathrm{sr}}\left(\chi, \xi, t_{h}\right) P\left(\chi, \xi, t_{h}\right) \delta A(\chi, \xi)}{\sum_{(\chi, \xi) \in \mathrm{SR}_{m}} \delta A(\chi, \xi)}$.

Here, $P\left(\chi, \xi, t_{h}\right)$ represents the total precipitation over the point $(\chi, \xi)$ during day $t_{h}$, and $\delta A(\chi, \xi)$ represents the area of each grid cell.

The moisture fraction computed with Eq. (2.4), is used to quantify the amount of precipitation generated over the sink grid cell $\left(\chi, \xi, t_{h}\right)$ from any specific source region sr.

Here, we calculate the moisture fraction contribution from different evaporative sources for two cases: first by dividing the entire domain into 27 different source regions and considering India as the common sink, and, second, by considering the core monsoon zone (Rajeevan et al. 2010) as the sink. The core region selected (Fig. 4a in Rajeevan et al. 2010) is roughly from $18.0^{\circ}$ to $28.0^{\circ} \mathrm{N}$ and from $65.0^{\circ}$ to $88.0^{\circ} \mathrm{E}$ (shown as the hatched region in Fig. 1a). The first case provides insights about the contribution of different terrestrial and oceanic sources to the precipitation over India, whereas the second case shows the variability of contributions from different sources to the monsoon rainfall over the core zone. The fraction of moisture originating from a source region $S R_{m}$ that contributes to the ISMR is calculated as

$$
\begin{aligned}
R\left(\chi, \xi, t_{h}\right)_{\varepsilon(\text { Indianlandmass })} & \sum_{S_{i} \in \mathrm{SR}_{m}}\left[\prod_{j=1}^{S_{i}-1} \alpha_{j}\left(\chi, \xi, t_{h}\right)\right] \\
& \times R_{S_{i}}\left(\chi, \xi, t_{h}\right) .
\end{aligned}
$$

Here, $S_{i}$ corresponds to segments of the trajectories that fall in the source region $\mathrm{SR}_{m}$. The percentage moisture contribution at each grid $P\left(\chi, \xi, t_{h}\right)$ from any source region $\mathrm{SR}_{m}$ is calculated as follows:

$$
P_{r}\left(\chi, \xi, t_{h}\right)=\frac{R\left(\chi, \xi, t_{h}\right) P\left(\chi, \xi, t_{h}\right) \times 100}{P\left(\chi, \xi, t_{h}\right)},
$$


(a) Contributions from the land sources (\%)

\begin{tabular}{|c|c|c|c|c|}
\hline Ganga basin & southern Peninsular India & South-central forest & Himalayan forest \\
\hline
\end{tabular}

(b) Contributions from the oceanic sources (\%)

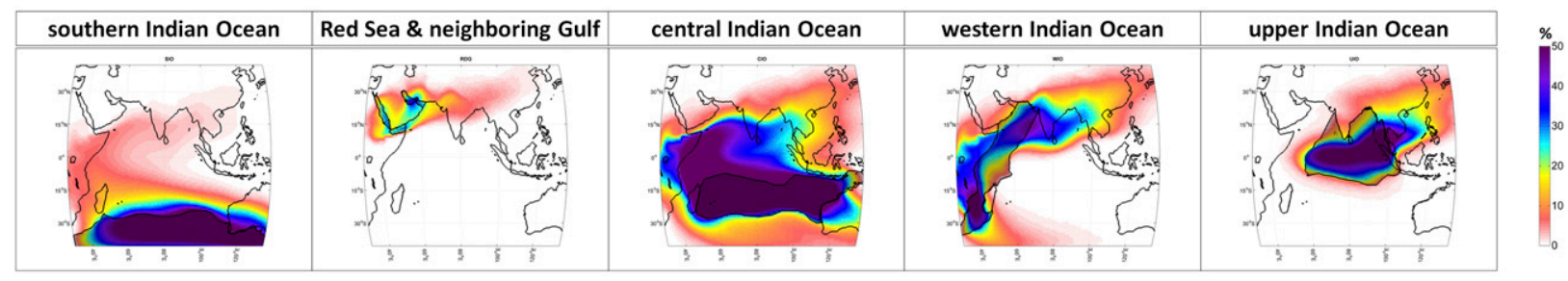

source region

FIG. 3. Mean JJAS moisture (\%) that originated from (left)-(right) different (a) land and (b) oceanic regions. The color scale ranges from $0 \%$ to $50 \%$ in increments of $10 \%$.

where $P\left(\chi, \xi, t_{h}\right)$ represents the total precipitation at sink $\left(\chi, \xi, t_{h}\right)$.

\section{Results and discussion}

\section{a. Oceanic and terrestrial contributors}

Here, we present the contributions of atmospheric moisture from different evaporative sources to ISMR. Table 1 shows the mean precipitation and fraction of moisture originating from different sources that contribute to the ISMR. Among the terrestrial regions, 12 [Ganges basin (GB)], 3 (central Asia), 14 (southcentral India), 11 (northwestern Indian subcontinent), and 22 (Africa) are the main sources of atmospheric moisture, whereas 25 [western Indian Ocean (WIO)], 20 [central Indian Ocean (CIO)], 19 [Red Sea and neighboring gulf (RDG)], 26 [upper Indian Ocean (UIO)], and 4 [southern Indian Ocean (SIO)] are the main contributors among oceanic sources. The abovementioned sources together account for $72 \%$ of total precipitation in ISMR. Here, it is important to note that the subdivision of the entire domain into terrestrial and oceanic regions is done only for the identification of the key sources. Once the major source regions are identified, we analyzed their impact on the monsoon seasonal total and interannual variability of the ISMR. The moisture contributions from these major moisture source regions are discussed hereafter.

Figure 3 shows the mean seasonal moisture contribution from major subcontinental land and oceanic moisture sources to ISMR. Among land evaporative sources, the highest amount of water vapor comes from the Ganges basin (12) (maximum $\sim 15 \%$ in Fig. 3a, first four panels from left). This can be attributed to the high amount of recycling within the Ganges basin, which in turn is associated to the large-scale agricultural practices and associated evapotranspiration. The moisture evaporated from the Ganges basin (12) is carried to northeastern India (16), the Himalayan ranges (15), southeast China, and the Tibetan Plateau (7) as a result of strong southwesterly winds. Recycling within the Ganges basin is an important precipitation mechanism, which accounts for $\sim 15 \%$ of rainfall. South-central India (14), which has relatively higher density of forest cover and high atmospheric moisture from high evapotranspiration, provides water vapor to central India, eastern India, and south-central India (14). Recycling accounts for around $5 \%-10 \%$ of total precipitation over south-central India (14) (Fig. 3). However, the contribution from south-central India to ISMR is not high $(\sim 5 \%)$. Water vapor from central Asia (3; figure not shown), the northwestern Indian subcontinent (11; figure not shown), eastern Africa (22; figure not shown), and southern India (13) has very low influence $(8 \%)$ on the precipitation over the subcontinent.

Most of the atmospheric moisture contributing to ISMR originates from the western Indian Ocean (25), with maximum contribution to rainfall over the Western Ghats ( $\sim 40 \%$ in Fig. 3), south peninsular India ( $30 \%$ in Fig. 3), and central India ( $\sim 25 \%$ in Fig. 3). Factors such as African orography (Chakraborty et al. 2009), strong southwesterly current due to the Coriolis effect, and the low pressure center over Somalia help in diverting the moisture flux from the central and southern 


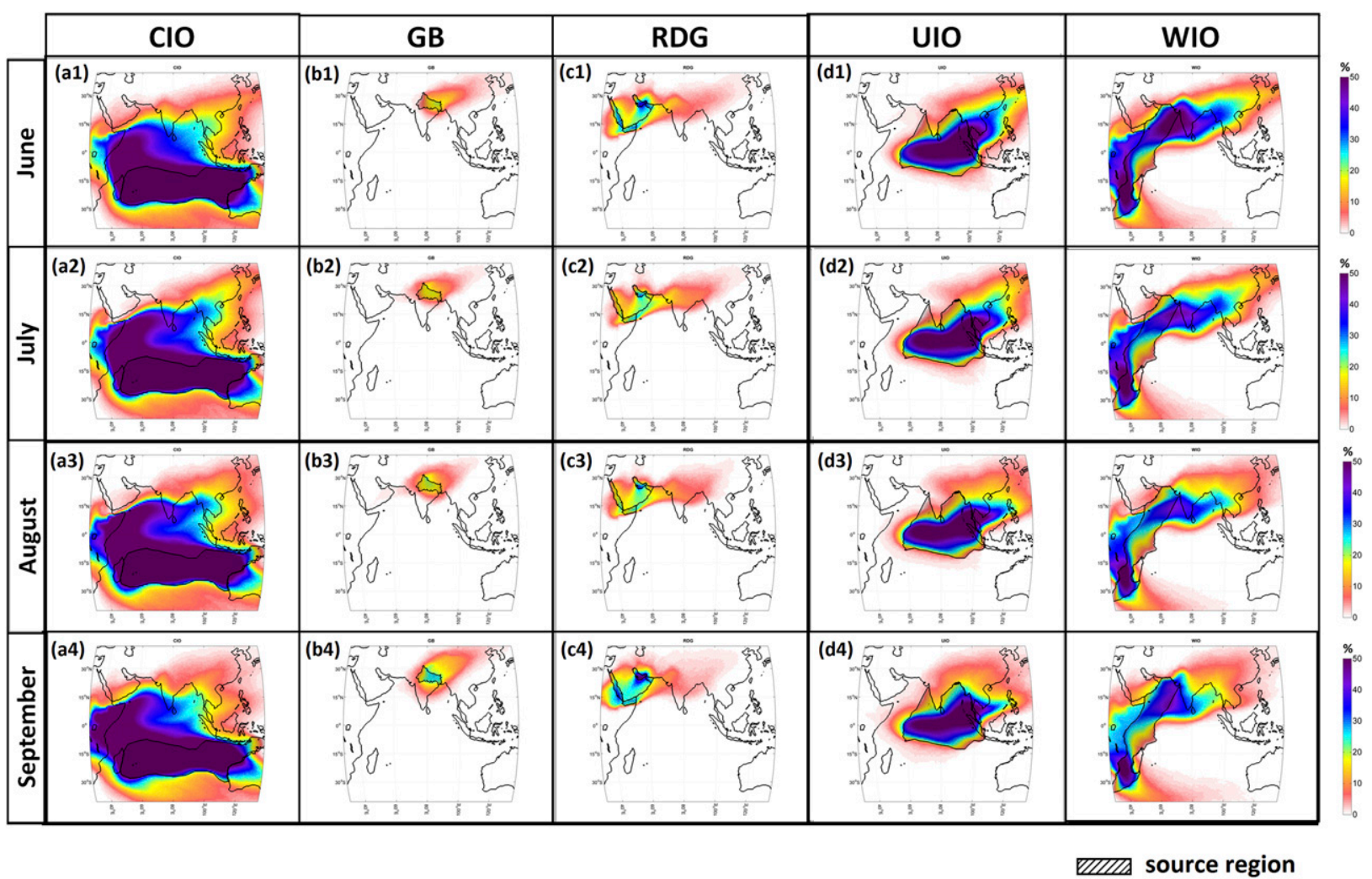

FIG. 4. As in Fig. 3, but for ocean and subcontinental land regions during (top)-(bottom) June, July, August, and September.

Indian Ocean to the Arabian Sea and then toward the Indian landmass. The impact of the Somali low-level jet on monsoon rainfall has been reported in multiple studies (Chakraborty et al. 2009; Ordóñez et al. 2012, 2013), but its quantification at daily time scale and its impact on seasonal rainfall have not yet been reported, to the best of our knowledge. Here, we find that the western Indian Ocean contributes significantly to the ISMR, especially during the initial phase of the monsoon. Water vapor from the western Indian Ocean (25) is also an important source of precipitation over the Arabian Sea ( $>50 \%$ in Fig. 3) and the Bay of Bengal ( $\sim 30 \%$ in Fig. 3 ). However, this contribution diminishes as water vapor trajectories move farther toward Indochina.

The central Indian Ocean (20) is the second largest contributor to the atmospheric moisture. The basic pathway of atmospheric moisture transport from the central Indian Ocean to the Indian landmass can be described as follows.

High pressure and cross-equatorial flow during the summer monsoon promote moisture divergence from the central Indian Ocean (20) to the western Indian Ocean (25) and upper Indian Ocean (26).This provides additional moisture to the existing flux from the western
Indian Ocean (see Hastenrath and Greischar 1993). As shown in Fig. 3, the water vapor from the central Indian Ocean directly provides moisture for precipitation over the Arabian Sea [>40\% in Fig. 3 and Figs. 4a(1)-(4)] and southern peninsular India $[\sim 30 \%$ in Fig. 3 and Figs. $4 a(1)-(4)]$. Our findings are consistent with Gimeno et al. (2010), where the Arabian Sea, central Indian Ocean, and the Zanzibar Current were identified as major contributors to June-August rainfall over the Indian subcontinent.

The upper Indian Ocean (26) is a major source of precipitation over Indochina and northeastern India. Its contribution to the seasonal precipitation over India is relatively small $[<10 \%$ in Fig. 3 and Figs. $4 d(1)-(4)]$ as a result of strong westerly moisture transport. Although the size of the Red Sea and the neighboring gulf region is small, its contribution to the ISMR is nonnegligible, specifically over northwestern India, where rainfall is low. We find that the contribution from the southern Indian Ocean (4) to ISMR is also very low $(<5 \%$ in Fig. 3), as opposed to earlier studies (Bosilovich and Schubert 2002). The larger influence of the southern Indian Ocean, as observed by Bosilovich and Schubert (2002), may be related to some of the differences between their study and the present analysis, including 
differences in horizontal resolution, shape, size, and extent of source regions, as well as different water accounting methods [Bosilovich and Schubert (2002) use water vapor tracers in a $3 \mathrm{D}$ atmospheric model].

Recently some studies identified the key moisture sources for the Indian summer monsoon rainfall (Gimeno et al. 2010; Ordóñez et al. 2012; Mei et al. 2015). Gimeno et al. (2010) considered the WIO and $\mathrm{CIO}$ as the sources of moisture in forward tracking with a Lagrangian approach. They found that the contribution from the CIO is at a maximum over the western Indian Ocean and not over the Indian landmass, which is consistent with our Fig. 3b. The WIO makes the largest contribution to the Indian landmass. Ordóñez et al. (2012) considered western India as the sink and identified the Somali jet as the major source of moisture during the monsoon. We found that the travel path of the Somali jet coincides with WIO, which is in agreement with Ordoñez et al. (2012). Mei et al. (2015) also identified the Arabian Sea (location similarly to our WIO) as the major moisture source. In addition, they also found a flat pattern for the contribution from the Bay of Bengal. Both of these results are in agreement with our findings. However, it is important to point out that Mei et al. (2015) also used the DRM, so the methodologies are the same.

\section{b. Temporal variability in oceanic and terrestrial contributions}

We identify five major moisture sources for the ISMR: the western Indian Ocean (25), central Indian Ocean (20), upper Indian Ocean (26), Ganges basin (12), and Red Sea and neighboring gulf (19). Temporal variability of ISMR is often associated with the strength of atmospheric moisture transported from these evaporative sources. Figure 4 shows the contribution of moisture to ISMR from these major sources during June, July, August, and September, separately. The transport of atmospheric moisture from the central Indian Ocean (20) to the Indian subcontinent starts from June, reaches a maximum during July and August, and decays during September when the monsoon starts to retreat. The water vapor from the central Indian Ocean also provides moisture to the western Indian Ocean (25) and upper Indian Ocean (26), with the highest amount during July and August when the mean low-level westerly flow dominates the atmospheric circulation (Hastenrath and Greischar 1993; Wajsowicz and Schopf 2001). Therefore, the peak of seasonal rainfall during July and $\mathrm{Au}-$ gust is observed to be associated with the strength of moisture transport from the central Indian Ocean.

The western Indian Ocean (25), which is the major source of atmospheric moisture for ISMR, has its highest influence during June ( $>50 \%$ in western India). The contribution of moisture to western and southern India decreases during July and August. However, for the same period, it continues to provide a significant amount of moisture to the Ganges basin and northeastern India. During September, with the retreat of the monsoon over the subcontinent, and as a result of relatively less moisture transport from the central Indian Ocean to the western Indian Ocean, the contribution from the western Indian Ocean to the ISMR is limited to the Western Ghats and southern India. Among these five moisture sources, the western Indian Ocean, through the low-level Somali jet, acts as a primary source of atmospheric moisture, which is consistent with the conclusions of Bosilovich and Schubert (2002), though the boundaries of the source regions vary across studies. Our selection of the boundaries over the oceans is comparatively more realistic than in earlier studies, as here these boundaries are based on regions with similar moisture flux divergence/convergence.

The continuous supply of moisture from the Indian Ocean and subcontinental land remains active during the entire monsoon season. The upper Indian Ocean (26) behaves differently from other oceanic sources. The water vapor from the Bay of Bengal provides more moisture during the final phase of the summer monsoon (i.e., September), when the westerly flow is weaker. Regions like northeastern and south-central India get more rainfall from the Bay of Bengal region by the end of the monsoon. The northeasterly flow starts to build up from September onward, becoming more prominent during the winter monsoon.

The Red Sea and the neighboring gulf region provide more moisture to ISMR during July $[\sim 15 \%$ in Figs. $4 c(1)-(4)]$ than in September $[\sim 5 \%$ in Figs. 4c(1)-(4)]. Interestingly, a significant amount of moisture comes from this source during the peak of the monsoon in the rainfall weak region of northwest India. Among the terrestrial sources, the Ganges basin acts as a main evaporative source for the precipitation over north and central India. The transport of atmospheric moisture from the Ganges basin increases as the monsoon season progresses. At the initial phase of the monsoon, the Indian Ocean is a strong moisture source. The subsequent recharge of soil moisture makes the evapotranspiration over the Ganges basin become active after the onset of the monsoon. This finding is consistent with our earlier work (Pathak et al. 2014), where the precipitation recycling within the Ganges basin is more prominent during August and September. Here it is important to note that soil moisture memory is considered as that simulated by reanalysis and hence is only as good as the model's representation of the dominant soil moisture 


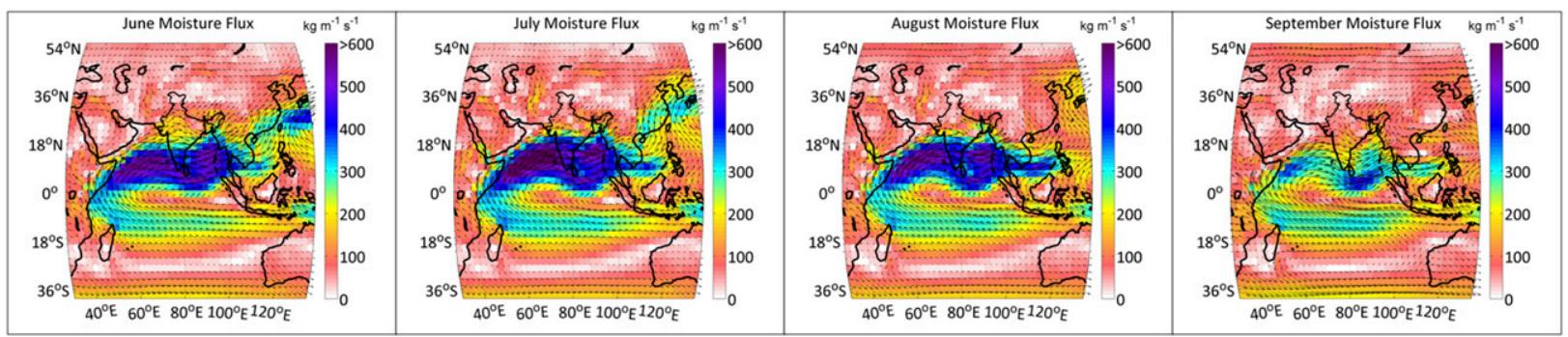

FIG. 5. Vertically integrated moisture flux during (left)-(right) June, July, August, and September. The color scales run from 0 to $>600$ in intervals of $100 \mathrm{~kg} \mathrm{~m}^{-1} \mathrm{~s}^{-1}$

processes. Furthermore, our simulations do not include land-use/land-cover (LULC) change; they are based on the reanalysis land cover. The tropospheric temperature gradient over the Indian subcontinent, which is responsible for land-sea thermal contrast, is maintained by higher evapotranspiration rates after the monsoon onset (Roxy et al. 2015). It is also observed that the peak monsoon rainfall occurs during a period when all the oceanic and terrestrial sources contribute significantly to the ISMR.

Seasonal variations in the moisture flux transport are shown in Fig. 5. The moisture flux fields show that the southwesterlies with oceanic moisture are primarily influencing southern Indian precipitation. They have comparatively less influence over north India and the Ganges basin, specifically during the peak and end of the monsoon. The circulation over the Ganges basin is dominated by the moisture flux generated within the landmass and the Bay of Bengal. The moisture that originated from the Ganges basin results in precipitation over the same region, with a high recycling ratio, as shown in Figs. 4b(1)-(4).

\section{c. Evaporative sources for precipitation over the core monsoon zone}

To study the role of different moisture sources on the strength of the ISMR, we quantify the atmospheric moisture transport from different evaporative sources to a common sink over central India, known as the core monsoon zone (Fig. 6b). The monsoon rainfall over the core monsoon zone is significantly correlated with the rainfall over major parts of India, except for the Himalayan foot hills, and northeast India (Rajeevan et al. 2010). Table 2 presents the correlation coefficient of the core monsoon zone rainfall with the contributions from different oceanic and terrestrial evaporative sources. Here, it is important to note that the moisture contributions from different regions are correlated, and their individual impacts on the variability are hard to separate. This is also prominent in Table 2 (top), which shows the high cross correlation among the contributions from different sources. To understand their individual impacts, we use the conventional statistical measure of partial correlation, and the results are also presented in Table 2 (bottom). The results show that the seasonal precipitation over the core monsoon zone is strongly correlated with moisture transport from the western Indian Ocean, Ganges basin, Red Sea and neighboring gulf, and upper Indian Ocean. These sources control the interannual variability of ISMR. The western Indian Ocean (25) has highest seasonal correlation not only with the seasonal rainfall at the core monsoon zone, but also with moisture contributions from different terrestrial and oceanic sources. The high correlation of the Red Sea moisture fraction with rainfall over the core monsoon zone is due to strong westerly flow during JJAS.

Figure 6 shows the contribution from different evaporative moisture sources to precipitation over the core monsoon zone. As expected, a major proportion of water vapor comes from the western Indian Ocean (25) and Ganges basin (12) (Fig. 6a). Moisture from the central Indian Ocean (20) and upper Indian Ocean (26) also contributes to the precipitation over the core monsoon zone. However, this contribution is relatively small as compared to the contribution from the western Indian Ocean (25). We find that the contribution per unit area from the Red Sea and neighboring gulf (19) is quite high compared with other regions. The southcentral forest region (14) is also a moisture source for precipitation over the core monsoon zone, but its contribution is small $(\sim 5 \%)$. Figure $6 \mathrm{c}$ shows the climatology of the contributions from different evaporative sources and the rainfall over the core monsoon zone. The climatology of the contribution from the western Indian Ocean shows a bell-shaped curve with maximum contribution during July. The contributions from the central and upper Indian Ocean form a flat-shaped curve for climatology (Fig. 6c). It is observed (Fig. 6c) that the peak in Indian monsoon rainfall occurs between the end 


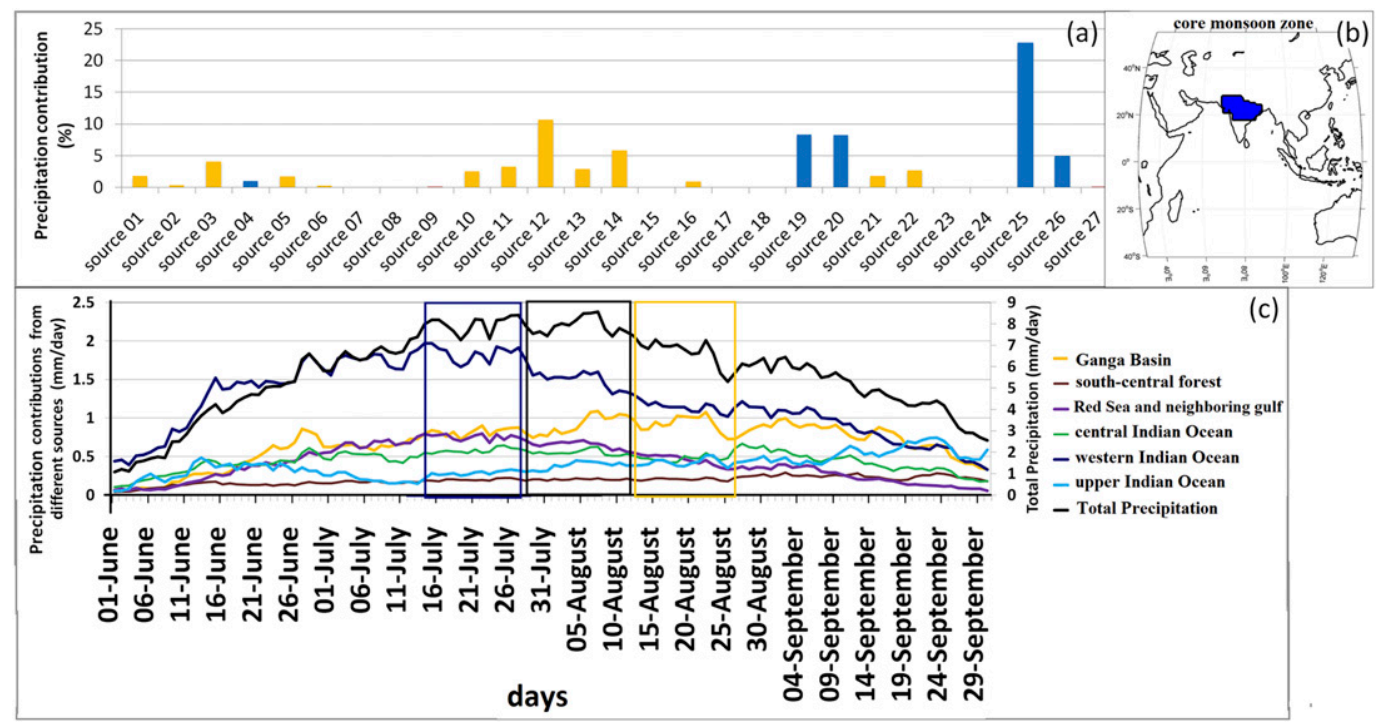

FIG. 6. (a) Percentage of moisture contribution from different sources to mean precipitation and (b) their climatology over core monsoon zone originating from (c) different land and oceanic sources. Here, the rectangular boxes represent three time slices: viz., period 1 (peak of WIO contribution), period 2 (total precipitation), and period 3 (GB contribution).

of July the beginning of August, and it is slightly later than the occurrence of the peak of contribution from the WIO and slightly earlier than the largest contributions from terrestrial sources. During the initial phase of the monsoon, precipitation over the core monsoon zone is highly influenced by western Indian Ocean (25). The contributions from the western Indian Ocean decrease with the advancement of the monsoon. The upper Indian Ocean and terrestrial sources, such as the Ganges basin and south-central India (not shown), continue to contribute more during the final phase of the monsoon.

For further analysis, we consider three time slices of 15 days duration around the peak of WIO contributions (period 1: 15-27 July), peak monsoon rainfall (period 2: 28 July-12 August), and maximum GB contributions (period 3: 13-26 August), as shown by three rectangular boxes in Fig. 6c. Figure 7a(4) shows the area-averaged moisture contribution from different evaporative sources during these three time slices. We find that the contribution from WIO is reduced during period 2 (the peak of Indian monsoon rainfall), and further reduction is observed when the contribution from the Ganges basin is maximum, during period 3 [Figs. 7c(1)-(4)]. The opposite behavior is observed in the moisture contributions from the Ganges basin. The contribution from CIO slightly decreases with time, whereas the contribution from the UIO increases with time. However, the net increases or decreases in moisture contributions from the CIO and UIO are very small. This results into flat-shaped climatologies as observed in Fig. 6c. Here, we conclude that the peak rainfall during July and August is attributed to the contribution from both oceanic and terrestrial sources.

\section{d. Variability during strong and weak monsoon years}

Skillful prediction of drought and flood due to variability in ISMR is still a challenge for climate models. One of the possible reasons is the inadequacy in modeling the complex atmospheric moisture transport from different oceanic sources. Previous studies have investigated the relationship of SST anomalies (Ashok et al. 2001; Joseph et al. 2013; Singh et al. 2015) and the cross-equatorial flow pattern (Chowdary et al. 2006; Singh et al. 2015) with the monsoon rainfall. However, the impact of the variability of tropical oceanic moisture transport is not quantified to a sufficient extent. Therefore, in the present study we attempt to find a relationship between the variability of the oceanic moisture source and summer monsoon variability during strong and weak monsoon years.

To understand the sensitivity of the core monsoon zone rainfall to the atmospheric moisture transport from different sources, we analyze the results for the strong, weak, and normal years. It is important to point out that we have used precipitation from the reanalysis product ERA-Interim for defining strong and weak monsoon years (as opposed to the products from the Indian Meteorological Department), in order to be consistent with our analysis with the DRM (which uses ERA-Interim fields). The strength of rainfall over different years is 
TABLE 2. Correlation coefficient of CMZ precipitation with precipitation contributions from different sources and correlation among different sources.

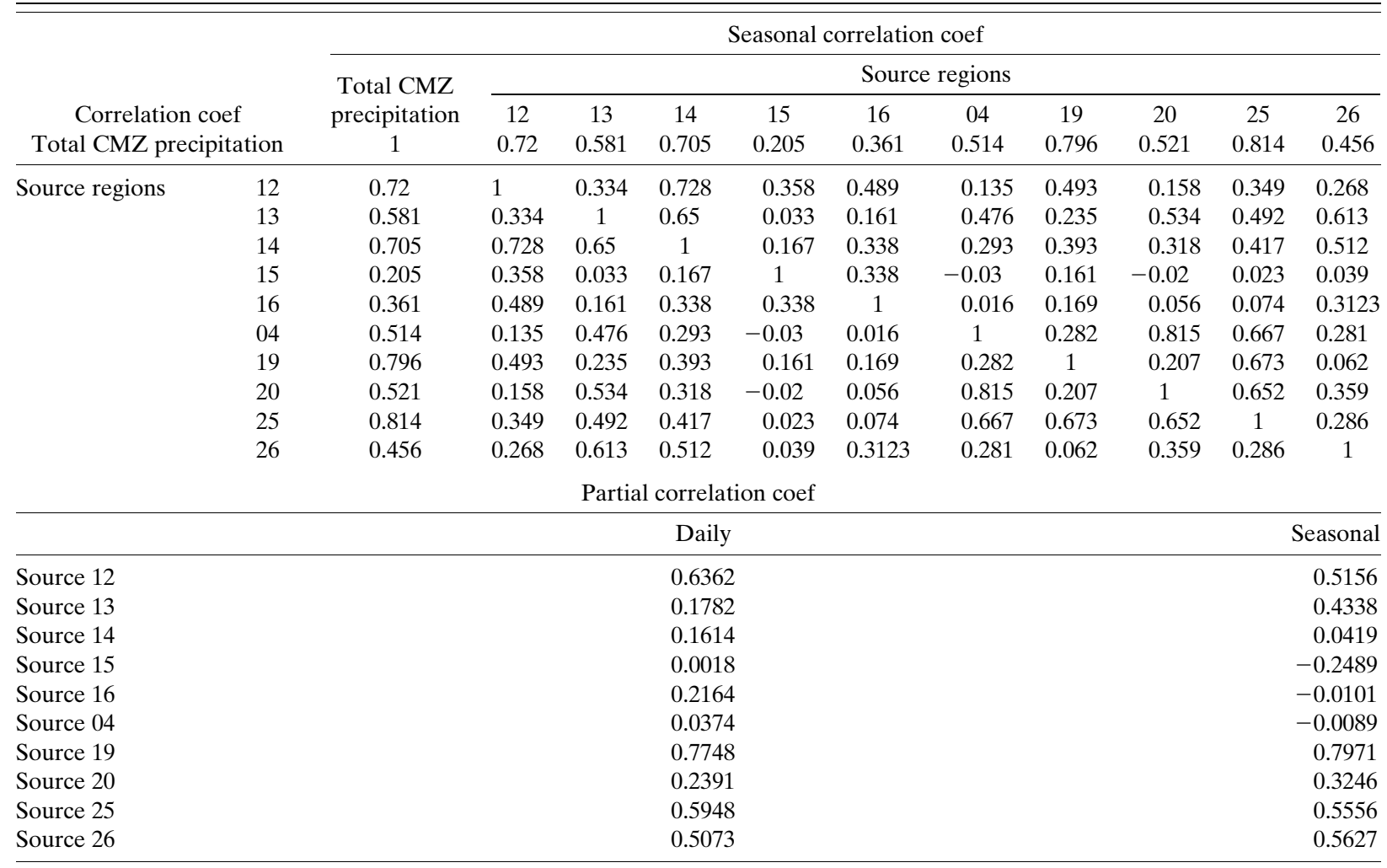

calculated based on the standardized precipitation anomaly over the core monsoon zone (CMZ) (Fig. 6b). Figure 8 shows the time series of standardized precipitation anomaly of JJAS rainfall over this zone for the selected time period. Here, the spatial average of the seasonal mean values is used to represent average precipitation over the CMZ. The years with a standard precipitation anomaly $\geq 1(\leq-1)$ are classified as strong (weak) rainfall years; all other years are classified as normal years. The composites from each of these groups represent strong rainfall, weak rainfall, and normal years. Figure 9 shows the contributions from major oceanic and terrestrial sources during strong and weak monsoon years. Generally, precipitation over the core monsoon zone is dominated by oceanic sources (southern Indian Ocean, Red Sea and gulf, central Indian Ocean, western Indian Ocean, and upper Indian Ocean), when compared with subcontinental terrestrial sources (Ganges basin, south-central forest region, northeast forest region, Himalayan forest, and southern India). However, their contributions during strong, weak, and normal monsoon years [Figs. 9(i)-(iii)] are different. During strong years, oceanic sources as well as terrestrial sources contribute significantly to the total precipitation, with very high oceanic contributions at the start and high terrestrial contributions during the end of the monsoon. During normal and strong monsoon years, increased evapotranspiration in the land region with the advancement of monsoon, as a result of good contributions from oceanic sources, sustains the monsoon and results in an increased monsoon spell duration [Fig. 9(i)]. Terrestrial sources (e.g., Ganges basin) provide moisture to the monsoon rainfall through evapotranspiration (ET), and this process depends on plant water availability. It is observed that, during weak monsoon years, low moisture flux from the ocean results into weaker rainfall in the initial phase of monsoon. The increased evapotranspiration by the end of the monsoon results in a substantial amount of recycled precipitation [Fig. 9(ii)]. Similar results were obtained by Dominguez and Kumar (2008), where recycling was observed to be significant during periods of low rainfall. We find that the variability of water vapor from the western Indian Ocean (25) and Ganges basin (12) has very high impact on the strength of seasonal rainfall. Therefore, we conclude that the prolonged and increased moisture supply from the western Indian Ocean (25) and Ganges basin (12) during the initial and 

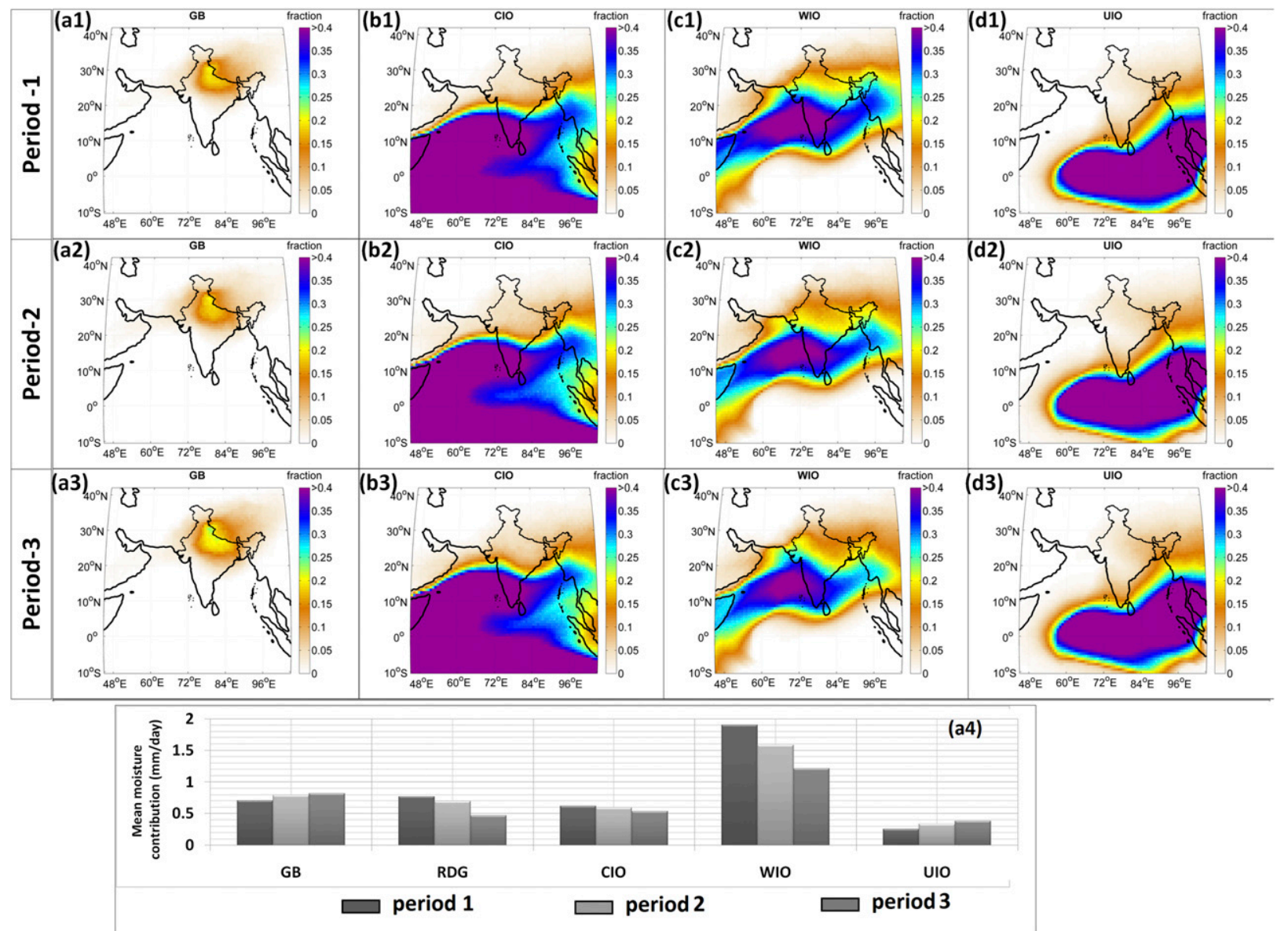

FIG. 7. Mean moisture contribution from different evaporative sources during (top)-(bottom) three time slices as in Fig. 6 and (left)(right) sources: GB, CIO, WIO, and UIO. The fraction color scale runs from 0 to $>0.4$ in increments 0.05 .

final phases of the monsoon period, respectively, results in a net strong seasonal rainfall.

The variability of the contributions from different sources for weak and strong rainfall years is clearly visible during the start and the end of the summer monsoon. Figures 10 and 11 show the difference (strong - weak years) in precipitation observed during June-September, originating from four main evaporative source regions (central Indian Ocean, Ganges basin, upper Indian Ocean, and western Indian Ocean). Strong monsoon years receive more rainfall from all evaporative sources, and the spatial distribution of moisture transport is different from that during weak monsoon years. During the Junes of strong years, oceanic sources provide more moisture over India than during weak monsoon years. The Ganges basin provides moisture to northeast India



FIG. 8. Standardized precipitation anomaly over the core monsoon zone during summer monsoon every year from 1981 to 2013. 


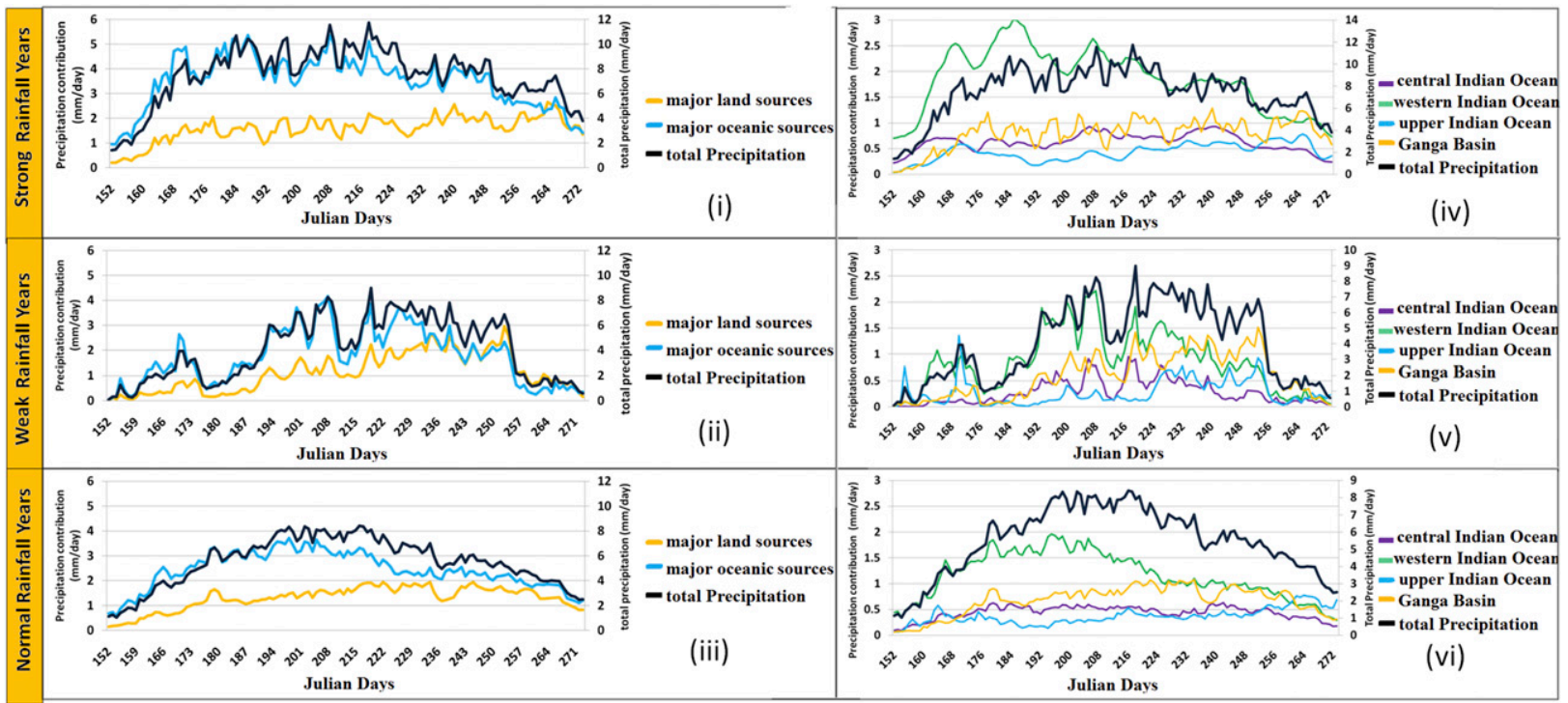

FIG. 9. Precipitation ( $\mathrm{mm} \mathrm{day}^{-1}$ ) originating from different sources during (top) strong, (middle) weak and (bottom) normal monsoon rainfall years vs Julian day from 152 to 272. (left) Major land (ocean) sources in yellow (blue) and totals in black. (right) Shown is precipitation from the central Indian Ocean (purple), western Indian Ocean (green), upper Indian Ocean (blue), and Ganges Basin (orange) sources, and total precipitation (black).

during weak monsoon years, whereas, during strong years, recycling within the Ganges basin is increased (Fig. 10). It is observed that atmospheric moisture transport from the western Indian Ocean has significant interannual variability. The core monsoon zone receives a large amount of atmospheric moisture from the western Indian Ocean during strong monsoon years. The cross-equatorial moisture transport from the central Indian Ocean to the Indian subcontinent and upper Indian Ocean is comparatively less during weak monsoon years compared to strong years. We also find that, during June in weak years, the moisture generated from the central
Indian Ocean gets precipitated in the same region, while for strong years it is being carried north, possibly because of strong northward propagation of monsoon winds.

Figure 12 shows the mean difference in evapotranspiration and precipitable water between the strong and weak rainfall years. Low oceanic moisture transport during weak rainfall years results in low precipitable water (Fig. 12). The evapotranspiration from land surfaces, especially for eastern India, is high during the end of the monsoon in weak rainfall years. This results in high recycled precipitation but is not sufficient to meet the deficiencies in the total precipitable water and,

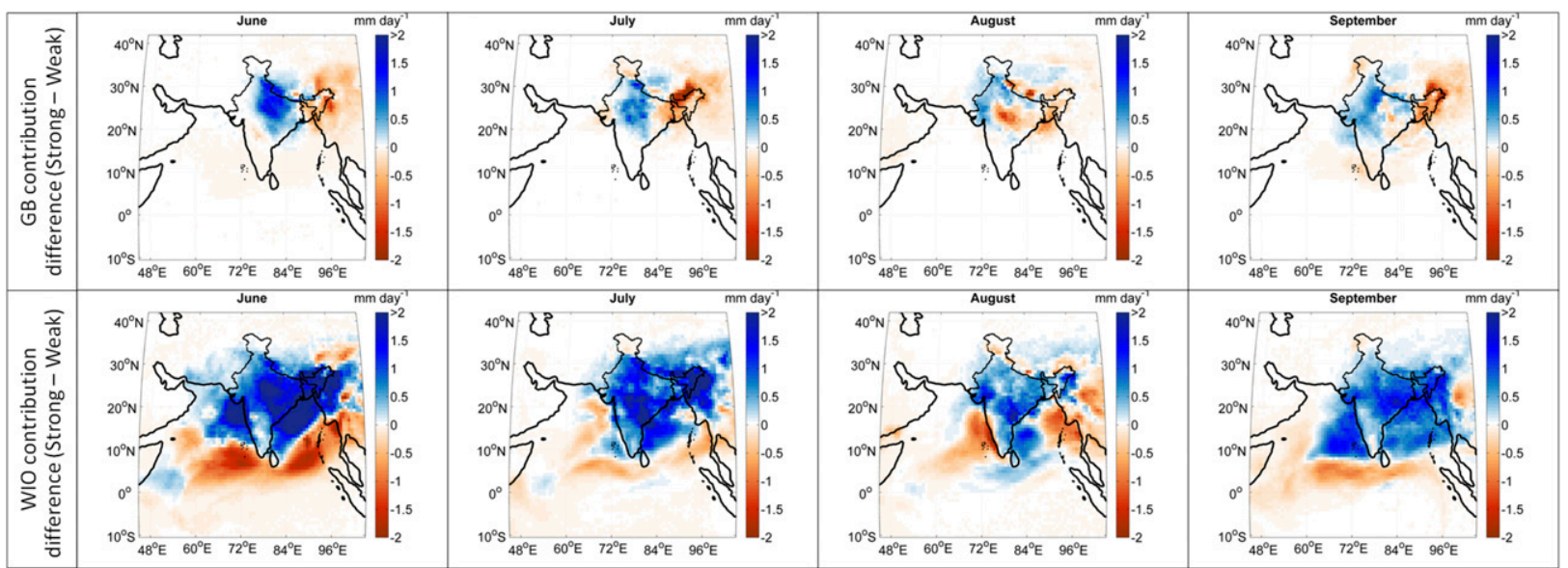

FIG. 10. Difference (strong - weak) in precipitation amount originating from the (top) GB and (bottom) WIO during (left)-(right) JJAS. The color scale runs from -2 to $>2$ in increments of $0.5 \mathrm{~mm}_{\text {day }}{ }^{-1}$. 


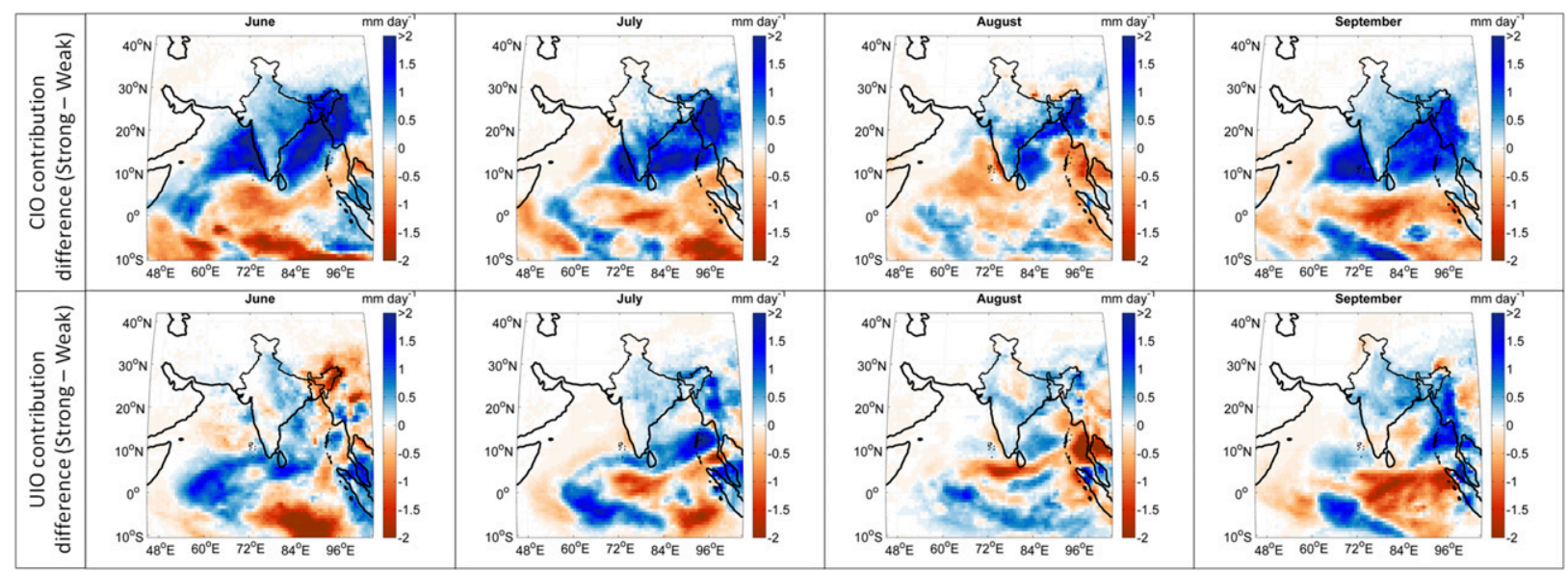

FIG. 11. As in Fig. 11, but originating from the CIO and UIO during JJAS.

subsequently, in the seasonal precipitation. Hence, their impacts are not visible in the increasing frequency of low rainfall years due to weakening of monsoon circulation, as implied by Roxy et al. (2014). Analysis of the trends in recycled precipitation involves understanding of changes in land use/land cover, and this is a nontrivial task. This may be considered as a potential subject for future research.

We find that the strong monsoon years have significant contributions from the western Indian Ocean during the initial phase of the monsoon, indicating an early onset of monsoon at the western coast. Sahana et al. (2015) have shown that the years with early monsoon onset (according to the vertically integrated moisture transport) are associated with normal/above-normal monsoon rainfall, which is consistent with our findings. The weak monsoon years experience a quick decay of the contributions from both oceanic and terrestrial sources [Figs. 9(ii),(v)]. This is probably associated with low recharge of soil moisture due to weak moisture transport from the ocean, which subsequently leads to low evapotranspiration. Sabeerali et al. (2012) have found an early shift in the retreat of the monsoon, and Sahana et al. (2015) have found a delayed shift in onset of monsoon during 1976/77, associated with a shift in the climate regime in the Pacific Ocean. Figure 13 shows the correlation between the eastern Pacific SST during May and the contributions from different oceanic sources to the core monsoon zone during June. Monthly mean of SST, which is obtained from ERA-Interim is spatially averaged over a region between $15^{\circ} \mathrm{N}-15^{\circ} \mathrm{S}$ and $180^{\circ}-$ $100^{\circ} \mathrm{W}$. It is observed that May Pacific SST has negative correlation $(-0.375 ; p$ value: 0.0265$)$ with southern Indian Ocean contribution. In addition, there is a negative correlation with the central Indian Ocean $(-0.275 ; p$ value: 0.1102$)$ and a negative correlation

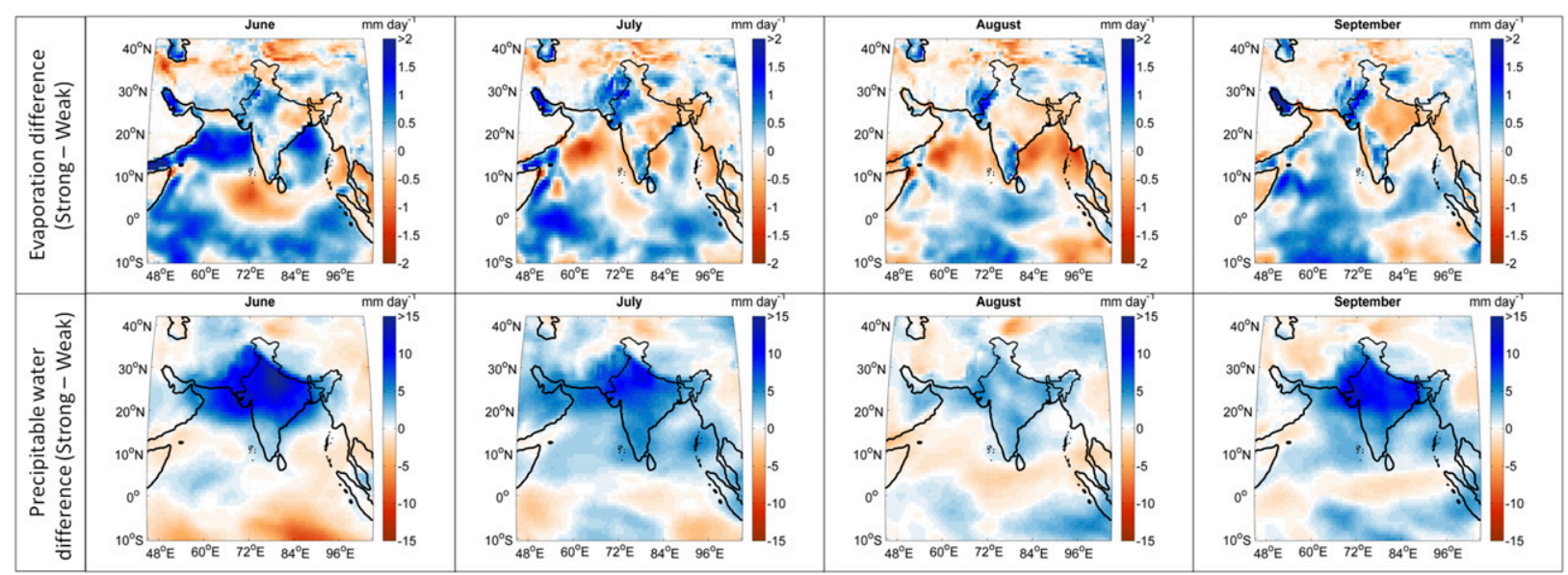

FIG. 12. Difference (strong - weak) in (top) evaporation and (bottom) precipitable water during (left)-(right) JJAS. The color scale for (top) is as in Fig.10; and for (bottom) runs from -15 to $>15$ in increments of $5 \mathrm{~mm}^{-1 a y}{ }^{-1}$. 

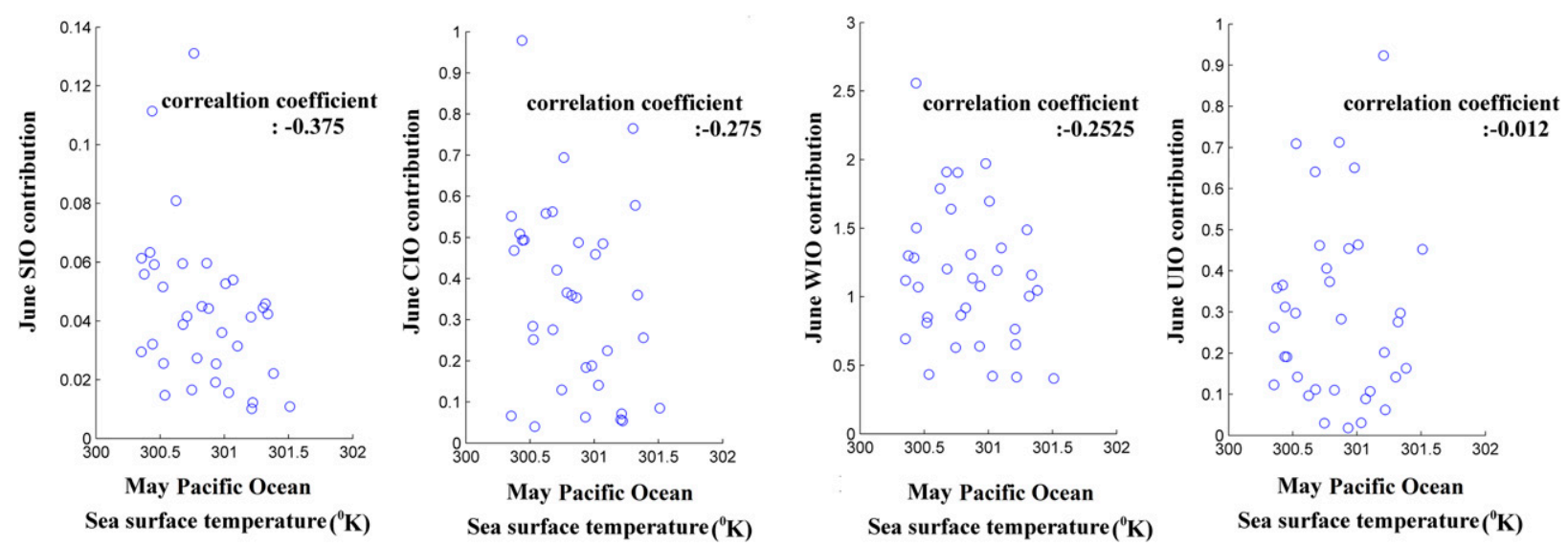

FIG. 13. Correlation of May Pacific SST with the moisture contributions to JJAS rainfall over core monsoon zone, from (left)-(right) different oceanic sources: SIO, CIO, WIO, and UIO.

with the contribution from the western Indian Ocean $(-0.2525 ; p$ value: 0.1432$)$. These findings suggest that a warmer Pacific Ocean is associated with a lower contribution of moisture from key oceanic sources to ISMR. This also indicates that the warm shift of Pacific SST during 1976/77 (Miller et al. 1994; Sahana et al. 2015; Sabeerali et al. 2012) is possibly one of the reasons behind recent weakening of Indian monsoon along with other reasons, such as warming of the western and southern Indian Ocean (Roxy et al. 2014, 2015). It has been hypothesized that the regime shift in the Pacific Ocean led to a delayed onset (Sahana et al. 2015) and an early retreat (Sabeerali et al. 2012) and hence a shortening of the monsoon period, along with a reduction in its strength. Testing of this hypothesis either needs longer reanalyses datasets (which are not available at fine resolution, such as $0.5^{\circ}$ ) or long-term model simulations, which may be a potential subject of future research.

The warming in the tropical Indian Ocean, especially in the western Indian Ocean, which has generally lower SST compared to the rest of the Indian Ocean, is observed to be responsible for a decrease in monsoon rainfall (Roxy et al. 2015). Here, we address this issue by studying the moisture contribution to the seasonal precipitation from different evaporative sources during warm Indian Ocean years (Fig. 14) and ENSO years. Figure 15 shows the seasonal anomalies of precipitation contributions from major moisture sources during the warm episodes of Indian Ocean warming and El Niño. The warming over the Indian Ocean enhances the contribution from the WIO (Fig. 15b) but reduces the precipitation over the core monsoon zone (Fig. 15a). The warming of the Indian Ocean results in a high convergence of moisture from the WIO. This is consistent with the findings of May (2011) and Turner and Annamalai (2012), which conclude that the warming over the Indian Ocean contributes to increased moisture transport to India. We observe a substantial increase in the precipitation contribution from the WIO; however, we see a decreased contribution from the CIO, Ganges basin, and UIO. The increased contribution from the WIO is not sufficient to meet the deficit because of the decreased contributions from other sources, which finally results in a deficit of rainfall years over the core monsoon zone. Low moisture fluxes from all the major sources during El Niño years result in negative anomalies of rainfall over the subcontinent (Figs. 15f-j).

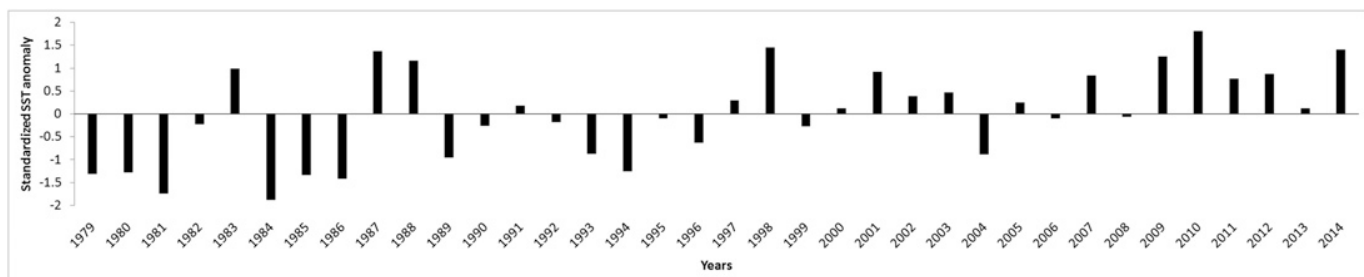

FIG. 14. Standardized SST anomaly over the IO from 1979 to 2014 . The years with anomaly $\geq 1(\leq 1)$ are considered as warm years (cool years). 


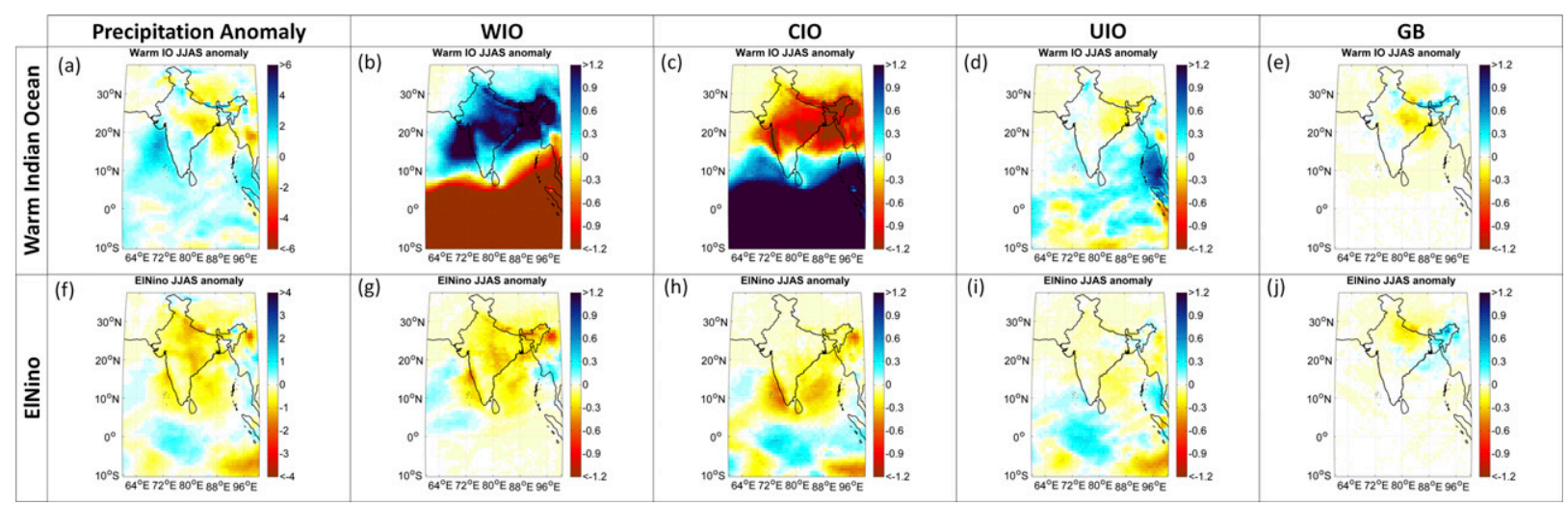

FIG. 15. Precipitation contribution anomaly from major moisture sources during (a)-(e) warm IO years and (f)-(j) El Niño years: (left)(right) total anomaly and contribution from WIO, CIO, UIO, and GB. The color scale for the total runs from (top) $<-6$ to $>6$ in increments of 2 for (a) and from $<-4$ to $>4$ in increments of 1 for (f). For the other panels, the color scale runs from $<-1.2$ to $>1.2$ in increments of 0.3 .

The interannual variability of the Indian monsoon originates from air-sea interactions, which vary at a range of scales. An example of such scale interactions is the association between monsoon intraseasonal oscillation (MISO) and interannual monsoon variability (Goswami 1998; Goswami and Ajaya Mohan 2001; Suhas et al.2012). Figure 16 shows the anomalies in moisture contributions from the major oceanic sources, the western Indian Ocean and central Indian Ocean, during strong and weak monsoon years. During the strong (weak) monsoon years, contributions from the western Indian Ocean have positive (negative) anomalies over northern and eastern India and negative (positive) anomalies over the equatorial Indian Ocean. Similarly, the CIO contributes more (less) over the southern Indian peninsula and less (more) to the

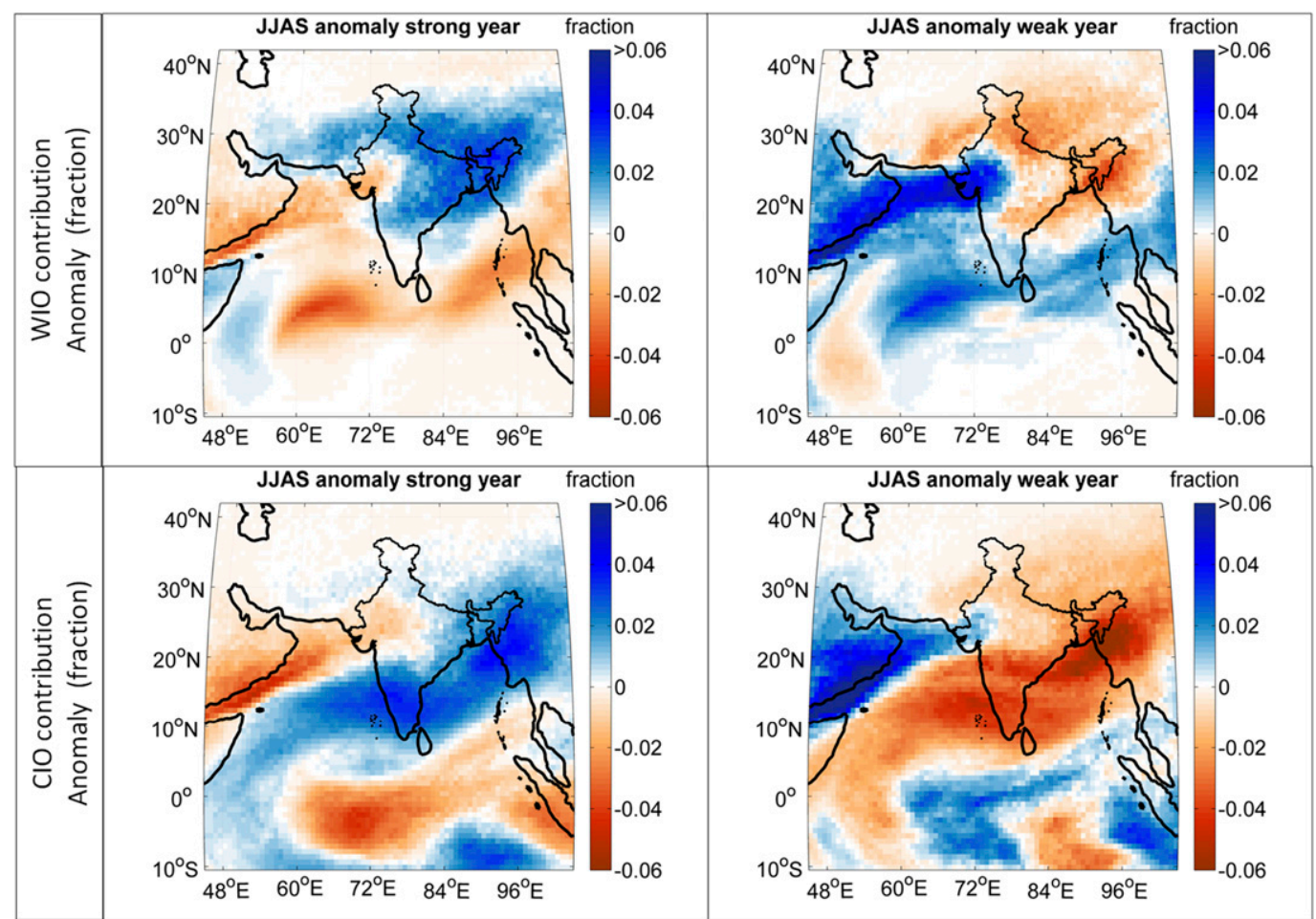

FIG. 16. Anomaly of JJAS moisture contribution (fraction) originating from (top) the WIO and (bottom) CIO during (left) strong and (right) weak rainfall years. 


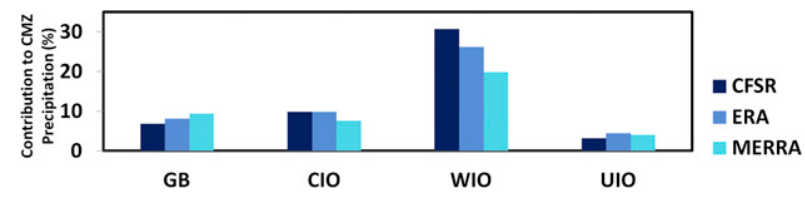

FIG. 17. Comparison of different reanalyses - CFSR (dark blue), ERA-Interim (light blue), and MERRA datasets (cyan) — in terms of precipitation contribution (\%) over the $\mathrm{CMZ}$ from major moisture sources: from left to right, GB, CIO, WIO, and UIO.

equatorial Indian Ocean during strong (weak) rainfall years. Therefore, a prominent north-south asymmetry is observed in the seasonal oceanic contributions between strong and weak monsoon years. These patterns are very similar to the MISO and provide a possible linkage (Goswami and Ajayamohan 2001) between the two scales of variability (intraseasonal and interannual). A relationship between MISO and interannual variability requires further study with respect to the moisture transport. Further analysis of the same requires very specific study of the contributions from different sources at intraseasonal scales, which is a potential area of future research.

The results are also tested with multiple datasets to make the findings robust, as there exists uncertainty across reanalyses (Shah and Mishra 2014). Figure 17 shows the comparison of different reanalyses (viz., CFSR, ERA-Interim, and MERRA datasets) in terms of precipitation contribution over the core monsoon zone from major moisture sources. We find similar conclusions of the WIO being the highest contributor among all the sources; though differences exist in the values. The relative contribution from one source with respect to others also remains similar across reanalyses. The differences are observed when we compare between the reanalyses in terms of the quantified contributions from land and oceanic sources. In CFSR, the contribution from land sources is less, and the contribution from oceanic sources is more, as compared to the other reanalyses.

We consider the composites of extremes that were widespread over the core monsoon zone to understand the relative contributions of different sources to extreme precipitation. We consider 99th-percentile rainfall as the threshold for extremes. The composites of contributions of different moisture sources are presented in Fig. S1 of the supplemental material. We find that the western Indian Ocean remains the major contributor of extreme events. Significant contribution from the major terrestrial source, the Ganges basin, is also observed. Contribution from the central Indian Ocean is observed at the eastern and western coasts. These results show the further need of event-based analysis possibly with a better regional reanalysis that captures spatial variability of extremes better.

\section{Summary and conclusions}

We analyzed the atmospheric moisture transport from different terrestrial and oceanic sources to monsoon rainfall in the Indian subcontinent. Most of the atmospheric moisture for ISMR comes from five main moisture sources: the western Indian Ocean (WIO), central Indian Ocean (CIO), upper Indian Ocean (UIO), Ganges basin (GB), and Red Sea and the neighboring gulf (RDG). We observe that the overall strength of the monsoon season is strongly influenced by the amount of moisture transport from the WIO during the onset of the monsoon and high terrestrial contributions, especially from GB during the retreat phase of the monsoon (i.e., during September). We find that the Bay of Bengal has very little contribution to ISMR during the initial phase of the monsoon compared to the WIO contribution, which is consistent with recent findings of Mei et al. (2015). However, this is not in agreement with an earlier finding, which states that Bay of Bengal is responsible for $45 \%-$ $55 \%$ of summer monsoon rainfall over India through monsoon depressions (Yoon and Chen 2005). It is, however, possible that the area-averaged moisture flux calculations from the reanalysis do not completely account for the net effect of the mesoscale features, such as the monsoon depressions and convection over Bay of Bengal. Mei et al. (2015), using a Lagrangian technique, studied the contribution from four different sources (viz., local, the Arabian Sea, the Bay of Bengal, and remote sources) to the ISMR, where contributions from local and remote sources were observed to be important. We also find that both local and remote regions (e.g., the WIO) are important sources; however, contributions from the southern Indian Ocean (SIO), which is located far south of the equator, is relatively small.

Gimeno et al. (2010) found the Indian Ocean, Arabian Sea, Zanzibar Current, and the Red Sea as the major oceanic sources for the Indian monsoon, which is consistent with this study. Our results illustrate the highly asymmetrical role of major oceanic moisture sources over India, where contributions from the $\mathrm{WIO}$ and $\mathrm{CIO}$ are significantly large, whereas the UIO has relatively smaller contributions to ISMR. Other studies, such as Bosilovich and Schubert (2002), Gimeno et al. (2010), and Van der Ent et al. (2010), were more focused on identification and quantification of contributions from different sources to the climatological seasonal rainfall; however, the impact of moisture source transport variability on ISMR was not 
studied in the past. Here, we quantify the role of moisture transport variability on the ISMR.

Previous studies (Pisharoty 1965; Saha and Bavadekar 1973; Ghosh et al. 1978; Sadhuram and Rao 1998; Levine and Turner 2012) have identified the WIO (Arabian Sea) as the most important contributor to the Indian monsoon rainfall. Based on atmospheric water budget and vapor flux considerations, they concluded that the contribution from WIO is higher as compared to that from south of equator. However, other studies find different results. For example, Saha (1970), Saha and Bavadekar (1973), and Sadhuram and Ramesh Kumar (1988) showed that the water vapor flux from the Southern Hemisphere has a dominant role in the rainfall across the Indian west coast as compared to the Arabian Sea evaporation. Here, to address this disagreement, we quantify the contributions from different moisture sources to the monsoon rainfall at the daily time scale. Our findings go beyond the identification and quantification of key moisture sources for the Indian monsoon and also present the following findings, which have not been reported in the literature to the best of our knowledge:

1) We find that the western Indian Ocean is the key source of moisture for the initial phase of the Indian monsoon. From the mid-monsoon season, the contribution from this moisture source decays, and other sources such as land surface ET become more active.

2) The moisture contribution from the central Indian Ocean to the Indian monsoon starts increasing from July and decreases by September.

3) The peak rainfall during July and August is a result of contributions from both oceanic and terrestrial sources. Oceanic sources contribute more during the initial period of monsoon, whereas terrestrial contribution is larger during the end of the monsoon. We have also found from the climatology that the time to reach the peak for the monsoon rainfall in a season does not coincide with the time of maximum oceanic contributions, which shows the importance of land surface feedback in monsoon rainfall.

4) The most important terrestrial moisture contributor to monsoon rainfall is the Ganges basin. The recycling of moisture within the Ganges basin is observed to be a maximum during August and September, as a result of increased soil moisture.

5) We have also analyzed the role of the variability in the atmospheric moisture contributions from different sources to the interannual variability of the Indian monsoon rainfall. We find that the strong monsoon years are associated with a predominant contribution from oceanic sources. The weak monsoon years have poor contributions from oceanic sources and are sustained by the ET from land surface processes.

Recently, a few studies have shown that there is an important contribution of subcontinental landmass to the ISMR (Van der Ent et al. 2010; Ordóñez et al. 2012; Pathak et al. 2014; Mei et al. 2015). This is consistent with similar analyses done over the North American monsoon region, which also have demonstrated the importance of terrestrial moisture on monsoonal precipitation (Hu and Dominguez 2015). In the present study, we evaluate the relative contributions from each subcontinental terrestrial source during ISMR. Our results show the importance of terrestrial sources, especially GB, to ISMR. However our results are not consistent with Ordóñez et al. (2012), where contributions from the northwestern part of the Indian subcontinent and recycling within western and southern India were also observed to be significant. The western Indian subcontinent region, which mostly covers Pakistan and the Thar Desert region, has significantly less vegetation cover, which results in a lower amount of recycling. On the other hand, the higher amount of vegetation cover over GB leads to $\mathrm{s}$ higher evapotranspiration rate and, hence, an increased amount of recycling. Here it is also important to note that the land surface processes and their interactions with the atmosphere are complex in nature. Hence, a considerable amount of uncertainty is associated with the reanalysis data of land surface ET and the computed amount of recycled precipitation.

The strength of the monsoon during strong and weak years is greatly influenced by the atmospheric moisture transport from oceanic and terrestrial regions. During strong monsoon years a strong land surface feedback due to high evapotranspiration leads to a prolonged monsoon season. We also found that the June rainfall during weak years contributes significantly to the seasonal mean rainfall, in contrast to earlier finding (Singh et al. 2015). We also find an association of the Pacific SST with the moisture contribution from oceanic sources. Recent studies suggest that the Pacific regime shift during 1976/77 is one of the causal factors for weakening of monsoon. However this needs to be further established with model simulations forced with different $\mathrm{Pa}$ cific SST conditions. Mishra et al. (2012) have shown that the interannual variability of Pacific SST controls the SST of the Indian Ocean and hence the Indian monsoon. Our results with the DRM are in agreement with this hypothesis. The western Indian Ocean, which is one of the key contributors to the Indian monsoon, has undergone warming during recent decades, which is responsible for decrease in monsoon rainfall (Roxy et al. 
2015). Use of the DRM with atmospheric fields from simulations with different SST forcing, as used in Roxy et al. (2015), could provide new scientific insights and may be considered as a future research subject.

Complex thermodynamic and dynamic processes come together to force monsoonal circulations and precipitation (Levine and Turner 2012). In this study, we have limited our analysis to delineating and quantifying the moisture sources of monsoonal precipitation. We believe this is an important step to understanding how variability of moisture contributions from different regions could be modified by changes in atmospheric dynamics and thermodynamics. For example, it is widely believed that El Niño-Southern Oscillation (ENSO) has a significant influence on the Indian monsoon rainfall. Hence, understanding moisture transport during ENSO years could provide much detailed information on the variability among moisture sources. However, in the present study we have not specifically studied the influence of ENSO on atmospheric moisture transport. The role of the moisture sources on the transition from the inter-monsoon to monsoon season is beyond the scope of this study, but it can be expected to be significant since the movement of the ITCZ across the equator will be a key factor in the ramp up of moisture transport into the Indian subcontinent.

Acknowledgments. The first two authors gratefully acknowledge the financial support provided by the Ministry of Earth Sciences, Government of India Grant MoES/PAMC/H\& C/35/2013-PC-II and Department of Science and Technology, Government of India Grant DST/CC/PR/06/2011. Amey Pathak and Subimal Ghosh acknowledge Prof. Raghu Murtugudde of the University of Maryland for his suggestions.

\section{REFERENCES}

Ashok, K., Z. Guan, and T. Yamagata, 2001: Impact of the Indian Ocean dipole on the relationship between the Indian monsoon rainfall and ENSO. Geophys. Res. Lett., 28, 4499-4502, doi:10.1029/2001GL013294.

Bosilovich, M. G., and S. D. Schubert, 2002: Water vapor tracers as diagnostics of the regional hydrologic cycle. J. Hydrometeor., 3, 149-165, doi:10.1175/1525-7541(2002)003<0149: WVTADO $>2.0 . \mathrm{CO} ; 2$.

Budyko, M. I., 1974: Climate and Life. Academic, 508 pp.

Burde, G. I., 2006: Bulk recycling models with incomplete vertical mixing. Part I: Conceptual framework and models. J. Climate, 19, 1461-1472, doi:10.1175/JCLI3687.1.

Chakraborty, A., R. S. Nanjundiah, and J. Srinivasan, 2009: Impact of African orography and the Indian summer monsoon on the low-level Somali jet. Int. J. Climatol., 29, 983-992, doi:10.1002/ joc. 1720.

Chowdary, J. S., C. Gnanaseelan, S. K. Sinha, and B. Thompson, 2006: A study of the variability of atmospheric and oceanic processes over the Arabian Sea during contrasting monsoons. Meteor. Atmos. Phys., 94, 65-85, doi:10.1007/ s00703-005-0166-3.

Dee, D. P., and Coauthors, 2011: The ERA-Interim reanalysis: Configuration and performance of the data assimilation system. Quart. J. Roy. Meteor. Soc., 137, 553-597, doi:10.1002/qj.828.

Dirmeyer, P. A., 1998: Land-sea geometry and its effect on monsoon circulations. J. Geophys. Res., 103, 11555-11572, doi:10.1029/98JD00802.

, and K. L. Brubaker, 2007: Characterization of the global hydrologic cycle from a back-trajectory analysis of atmospheric water vapor. J. Hydrometeor., 8, 20-37, doi:10.1175/ JHM557.1.

Dominguez, F., and P. Kumar, 2008: Precipitation recycling variability and ecoclimatological stability - A study using NARR data. Part I: Central U.S. plains ecoregion. J. Climate, 21, 5165-5186, doi:10.1175/2008JCLI1756.1.

- _— - X.-Z. Liang, and M. Ting, 2006: Impact of atmospheric moisture storage on precipitation recycling. J. Climate, 19, 1513-1530, doi:10.1175/JCLI3691.1.

Douville, H., and J. F. Royer, 1996: Sensitivity of the Asian summer monsoon to an anomalous Eurasian snow cover within the Meteo-France GCM. Climate Dyn., 12, 449-466, doi:10.1007/ BF02346818.

Friedman, I., G. I. Smith, J. D. Gleason, A. Warden, and J. M. Harris, 1992: Stable isotope composition of waters in southeastern California. 1. Modern precipitation. J. Geophys. Res., 97, 5795-5812, doi:10.1029/92JD00184.

Gadgil, S., 2003: The Indian monsoon and its variability. Annu. Rev. Earth Planet. Sci., 31, 429-467, doi:10.1146/annurev. earth.31.100901.141251.

Ghosh, S. K., M. C. Pant, and B. N. Dewan, 1978: Influence of the Arabian Sea on the Indian summer monsoon. Tellus, 30A, 117-125, doi:10.1111/j.2153-3490.1978.tb00825.x.

Gimeno, L., A. Drumond, R. Nieto, R. M. Trigo, and A. Stohl, 2010: On the origin of continental precipitation. Geophys. Res. Lett., 37, L13804, doi:10.1029/2010GL043712.

_ continental precipitation. Rev. Geophys., 50, RG4003, doi:10.1029/2012RG000389.

Goswami, B. N., 1998: Interannual variation of Indian summer monsoon in a GCM: External conditions versus internal feedbacks. J. Climate, 11, 501-522, doi:10.1175/1520-0442(1998)011<0501: IVOISM $>2.0 . \mathrm{CO} ; 2$

_ 2005: South Asian monsoon. Intraseasonal Variability in the Atmosphere-Ocean Climate System, 2nd ed. W. K. M. Lau and D. E. Waliser, Eds., Springer-Verlag, 19-61, doi:10.1007/ b138817.

__ and R. S. Ajaya Mohan, 2001: Intraseasonal oscillations and interannual variability of the Indian summer monsoon. J. Climate, 14, 1180-1198, doi:10.1175/1520-0442(2001)014<1180: IOAIVO $>2.0 . \mathrm{CO} ; 2$

Hansen, M. C., and Coauthors, 2013a: High-resolution global maps of 21 st-century forest cover change. Science, 342, 850-853, doi:10.1126/science. 1244693 .

_- - and Coauthors, 2013b: Global forest change. Department of Geographical Sciences, University of Maryland, accessed 15 November 2014. [Available online at http:// earthenginepartners.appspot.com/science-2013-global-forest.]

Hastenrath, S., and L. Greischar, 1993: The monsoonal heat budget of the combined ocean-atmosphere system in the Indian Ocean sector. J. Geophys. Res., 98, 6869-6881, doi:10.1029/ 92JC02956. 
Henderson-Sellers, A., K. McGuffie, and H. Zhang, 2002: Stable isotopes as validation tools for global climate model predictions of the impact of Amazonian deforestation. J. Climate, 15, 2664-2677, doi:10.1175/1520-0442(2002)015<2664: SIAVTF $>2.0 . \mathrm{CO} ; 2$.

Hu, H., and F. Dominguez, 2015: Evaluation of oceanic and terrestrial sources of moisture for the North American monsoon using numerical models and precipitation stable isotopes. J. Hydrometeor., 16, 19-35, doi:10.1175/JHM-D-14-0073.1.

Joseph, P. V., B. Gokulapalan, A. Nair, and S. S. Wilson, 2013: Variability of summer monsoon rainfall in India on interannual and decadal time scales. Atmos. Oceanic Sci. Lett., 6, 398-403, doi:10.3878/j.issn.1674-2834.13.0044.

Joussaume, S., J. Jouzel, and R. Sadourny, 1984: A general circulation model of water isotope cycles in the atmosphere. $\mathrm{Na}$ ture, 311, 24-29, doi:10.1038/311024a0.

Keys, P. W., R. J. van der Ent, L. J. Gordon, H. Hoff, R. Nikoli, and H. G. G. Savenije, 2012: Analyzing precipitation sheds to understand the vulnerability of rainfall dependent regions. Biogeosciences, 9, 733-746, doi:10.5194/bg-9-733-2012.

Koster, R., J. Jouzel, R. Souzzo, G. Russel, D. Rind, and P. S. Eagleson, 1986: Global sources of local precipitation as determined by the NASA/GISS GCM. Geophys. Res. Lett., 13, 121-124, doi:10.1029/GL013i002p00121.

Kottek, M., J. Grieser, C. Beck, B. Rudolf, and F. Rubel, 2006: World map of the Köppen-Geiger climate classification updated. Meteor. Z., 15, 259-263, doi:10.1127/0941-2948/2006/0130.

Levine, R. C., and A. G. Turner, 2012: Dependence of Indian monsoon rainfall on moisture fluxes across the Arabian Sea and the impact of coupled model sea surface temperature biases. Climate Dyn., 38, 2167-2190, doi:10.1007/ s00382-011-1096-z.

Lim, Y., K. Kim, and H. Lee, 2002: Temporal and spatial evolution of the Asian summer monsoon in the seasonal cycle of synoptic fields. J. Climate, 15, 3630-3644, doi:10.1175/ 1520-0442(2002)015<3630:TASEOT>2.0.CO;2.

Martinez, J. A., and F. Dominguez, 2014: Sources of atmospheric moisture for the La Plata River basin. J. Climate, 27, 67376753, doi:10.1175/JCLI-D-14-00022.1.

May, W., 2011: The sensitivity of the Indian summer monsoon to a global warming of $20^{\circ} \mathrm{C}$ with respect to pre-industrial times. Climate Dyn., 37, 1843-1868, doi:10.1007/s00382-010-0942-8.

Mei, R., M. Ashfaq, D. Rastogi, L. Leung, and F. Dominguez, 2015: Dominating controls for wetter South Asian summer monsoon in the twenty-first century. J. Climate, 28, 3400-3419, doi:10.1175/JCLI-D-14-00355.1.

Miller, A. J., D. R. Cayan, T. P. Barnett, N. E. Graham, and J. M. Oberhuber, 1994: The 1976-77 climate shift of the Pacific Ocean. Oceanography, 7, 21-26, doi:10.5670/oceanog.1994.11.

Mishra, V., B. V. Smoliak, D. P. Lettenmaier, and J. M. Wallace, 2012: A prominent pattern of year-to-year variability in Indian summer monsoon rainfall. Proc. Natl. Acad. Sci. USA, 109, 7213-7217, doi:10.1073/pnas.1119150109.

Ordóñez, P., P. Ribera, D. Gallego, and C. Peña-Ortiz, 2012: Major moisture sources for western and southern India and their role on synoptic-scale rainfall events. Hydrol. Processes, 26, 38863895, doi:10.1002/hyp.8455.

,,--- , and,- 2013 : Influence of Madden-Julian oscillation on water budget transported by the Somali low-level jet and the associated Indian summer monsoon rainfall. Water Resour. Res., 49, 6474-6485, doi:10.1002/wrcr.20515.

Pathak, A., S. Ghosh, and P. Kumar, 2014: Precipitation recycling in the Indian subcontinent during summer monsoon. J. Hydrometeor., 15, 2050-2066, doi:10.1175/ JHM-D-13-0172.1.

Pisharoty, P. R., 1965: Evaporation from the Arabian Sea and the Indian southwest monsoon. Proc. Symp. Meteorological Results of the International Indian Ocean Expedition, Bombay, India, India Meteorological Department, 22-26.

Rajeevan, M., S. Gadgil, and J. Bhate, 2010: Active and break spells of Indian summer monsoon. J. Earth Syst. Sci., 119, 229-247, doi:10.1007/s12040-010-0019-4.

Robock, A., M. Mu, K. Vinnikov, and D. Robinson, 2003: Land surface conditions over Eurasia and Indian summer monsoon rainfall. J. Geophys. Res., 108, 4131, doi:10.1029/ 2002JD002286.

Roxy, M. K., 2013: Sensitivity of precipitation to sea surface temperature over the tropical summer monsoon region-And its quantification. Climate Dyn., 43, 1159-1169, doi:10.1007/ s00382-013-1881-y.

— R. Kapoor, P. Terray, and S. Masson, 2014: The curious case of Indian Ocean warming. J. Climate, 27, 8501-8509, doi:10.1175/JCLI-D-14-00471.1.

,,,--- R. Murtugudde, K. Ashok, and B. N. Goswami, 2015: Drying of Indian subcontinent by rapid Indian Ocean warming and a weakening land-sea thermal gradient. Nat. Commun., 6, 7423, doi:10.1038/ncomms8423.

Sabeerali C. T., S. A. Rao, R. S. Ajayamohan, and R. Murtugudde, 2012: On the relationship between Indian summer monsoon withdrawal and Indo-Pacific SST anomalies before and after 1976/1977 climate shift. Climate Dyn., 39, 841-859, doi:10.1007/s00382-011-1269-9.

Sabin, T. P., C. A. Babu, and P. V. Joseph, 2013: SST-convection relation over tropical oceans. Int. J. Climatol., 33, 1424-1435, doi:10.1002/joc.3522.

Sadhuram, Y., and M. R. Ramesh Kumar, 1988: Does evaporation over the Arabian Sea play a crucial role in moisture transport across the west coast of India during an active monsoon period? Mon. Wea. Rev. 116, 307-312, doi:10.1175/ 1520-0493(1988)116<0307:DEOTAS $>2.0 . C O ; 2$.

— rainfall over India. J. Appl. Hydrol. 11, 63-70.

Saha, K. R., 1970: Air and water vapour transport across the equator in the western Indian Ocean during northern summer. Tellus, 22, 681-687, doi:10.1111/j.2153-3490.1970.tb00536.x.

_ cipitation over the Arabian Sea during the northern summer. Quart. J. Roy. Met. Soc., 99, 273-278, doi:10.1002/ qj. 49709942006 .

Sahana, A. S., S. Ghosh, A. Ganguly, and R. Murtugudde, 2015: Shift in Indian summer monsoon onset during 1976/1977. Environ. Res. Lett., 10, 054006, doi:10.1088/1748-9326/10/5/ 054006.

Salati, E., A. D. Olio, E. Matsui, and J. R. Gat, 1979: Recycling of water in the Amazon Basin: An isotopic study. Water Resour. Res., 15, 1250-1258, doi:10.1029/WR015i005p01250.

Sandeep, S., and R. S. Ajayamohan, 2014: Origin of cold bias over the Arabian Sea in climate models. Sci. Rep., 4, 6403, doi:10.1038/srep06403.

Shah, R., and V. Mishra, 2014: Evaluation of the reanalysis products for the monsoon season droughts in India. J. Hydrometeor., 15, 1591-1575, doi:10.1175/JHM-D-13-0103.1.

Singh, P., V. Vasudevan, J. S. Chowdary, and C. Gnanaseelan, 2015: Subseasonal variations of Indian summer monsoon with special emphasis on drought and excess rainfall years. Int. J. Climatol., 35, 570-582, doi:10.1002/joc.4004. 
Stohl, A., and P. James, 2004: A Lagrangian analysis of the atmospheric branch of the global water cycle. Part I: Method description, validation, and demonstration for the August 2002 flooding in central Europe. J. Hydrometeor., 5, 656-678, doi:10.1175/ 1525-7541(2004)005<0656:ALAOTA > 2.0.CO;2.

-, and —, 2005: A Lagrangian analysis of the atmospheric branch of the global water cycle. Part II: Earth's river catchments, ocean basins, and moisture transports between them. J. Hydrometeor., 6, 961-984, doi:10.1175/JHM470.1.

Suhas, E., J. M. Neena, and B. N. Goswami, 2012: Interannual variability of Indian summer monsoon arising from interactions between seasonal mean and intraseasonal oscillations. J. Atmos. Sci., 69, 1761-1774, doi:10.1175/JAS-D-11-0211.1.

Trenberth, K. E., J. W. Hurrell, and D. P. Stepaniak, 2006: The Asian monsoon: Global perspectives. The Asian Monsoon, B. Wang, Ed., Springer Berlin Heidelberg, 86-87, doi:10.1007/ 3-540-37722-0_2.

Tuinenburg, O. A., R. W. A. Hutjes, and P. Kabat, 2012: The fate of evaporated water from the Ganges basin. J. Geophys. Res., 117, D01107, doi:10.1029/2011JD016221.

Turner, A. G., and H. Annamalai, 2012: Climate change and the South Asian summer monsoon. Nat. Climate Change, 2, 587595, doi:10.1038/nclimate1495.
Van der Ent, R. J., H. G. Savenije, B. Schaefli, and S. C. SteeleDunne, 2010: Origin and fate of atmospheric moisture over continents. Water Resour. Res., 46, W09525, doi:10.1029/ 2010WR009127.

Wajsowicz, R. C., and P. S. Schopf, 2001: Oceanic influences on the seasonal cycle in evaporation over the Indian Ocean. J. Climate, 14, 1199-1226, doi:10.1175/1520-0442(2001)014<1199: OIOTSC $>2.0 . \mathrm{CO} ; 2$.

Winschall, A., S. Pfahl, H. Sodemann, and H. Wernli, 2014: Comparison of Eulerian and Lagrangian moisture source diagnostics-The flood event in eastern Europe in May 2010. Atmos. Chem. Phys., 14, 6605-6619, doi:10.5194/ acp-14-6605-2014.

Yang, S., K. M. Lau, S.-H. Yoo, J. L. Kinter, K. Miyakoda, and C.-H. Ho, 2004: Upstream subtropical signals preceding the Asian summer monsoon circulation. J. Climate, 17, 42134229, doi:10.1175/JCLI3192.1.

Yasunari, T., 1991: The monsoon year: A new concept of the climatic year in the tropics. Bull. Amer. Meteor. Soc., 72, 1331-1338, doi:10.1175/1520-0477(1991)072<1331:TMYNCO >2.0.CO;2.

Yoon, J. H., and T. C. Chen, 2005: Water vapor budget of the Indian monsoon depression. Tellus, 57A, 770-782, doi:10.1111/ j.1600-0870.2005.00145.x. 